ARTICLE

\title{
Dynamic relocalization of cytosolic type III secretion system components prevents premature protein secretion at low external $\mathrm{pH}$
}

Stephan Wimmi (10 1, Alexander Balinovic ${ }^{2,6}$, Hannah Jeckel (10 2,3, Lisa Selinger', Dimitrios Lampaki ${ }^{1,7}$, Emma Eisemann ${ }^{1,8}$, Ina Meuskens ${ }^{4}$, Dirk Linke (1) ${ }^{4}$, Knut Drescher (10) ${ }^{2,3}$, Ulrike Endesfelder (1) ${ }^{2,6}$ \& Andreas Diepold (10) $1,5 \otimes$

Many bacterial pathogens use a type III secretion system (T3SS) to manipulate host cells. Protein secretion by the T3SS injectisome is activated upon contact to any host cell, and it has been unclear how premature secretion is prevented during infection. Here we report that in the gastrointestinal pathogens Yersinia enterocolitica and Shigella flexneri, cytosolic injectisome components are temporarily released from the proximal interface of the injectisome at low external $\mathrm{pH}$, preventing protein secretion in acidic environments, such as the stomach. We show that in Yersinia enterocolitica, low external $\mathrm{pH}$ is detected in the periplasm and leads to a partial dissociation of the inner membrane injectisome component SctD, which in turn causes the dissociation of the cytosolic T3SS components. This effect is reversed upon restoration of neutral $\mathrm{pH}$, allowing a fast activation of the T3SS at the native target regions within the host. These findings indicate that the cytosolic components form an adaptive regulatory interface, which regulates T3SS activity in response to environmental conditions.

\footnotetext{
${ }^{1}$ Department of Ecophysiology, Max Planck Institute for Terrestrial Microbiology, Marburg, Germany. ${ }^{2}$ Max Planck Institute for Terrestrial Microbiology, Marburg, Germany. ${ }^{3}$ Department of Physics, Philipps-Universität Marburg, Marburg, Germany. ${ }^{4}$ Department of Biosciences, University of Oslo, Oslo, Norway. ${ }^{5}$ SYNMIKRO, LOEWE Center for Synthetic Microbiology, Marburg, Germany. ${ }^{6}$ Present address: Department of Physics, Mellon College of Science, Carnegie Mellon University, Pittsburgh, PA, USA. ${ }^{7}$ Present address: Max-Planck-Institut für Immunbiologie und Epigenetik, Freiburg, Germany.

${ }^{8}$ Present address: James Madison University, Harrisonburg, VA, USA. ${ }^{\circledR}$ email: andreas.diepold@mpi-marburg.mpg.de
} 
n order to increase survival chances in contact to eukaryotic host cells, both symbiotic and pathogenic bacteria have developed methods to influence host cell behavior. The type III secretion system (T3SS) injectisome is a molecular machinery used by various pathogenic bacterial genera, including Salmonella, Shigella, pathogenic Escherichia, Pseudomonas, and Yersinia to deliver molecular toxins-effector proteins-directly into the eukaryotic host cells. In this manuscript, T3SS refers to the virulence-associated T3SS. The common "Sct" nomenclature ${ }^{1,2}$ is used for T3SS components; when specifically referring to components of a particular species, the species initials are used as a prefix, e.g., YeSctD for Y. enterocolitica SctD. While the T3SS effectors differ among the different bacterial species ${ }^{3,4}$, and can have different functions in modulating the cytoskeleton, invading and escaping host cells or endosomes, or inducing host cell death (see reviews for animal pathogenic bacteria ${ }^{1,5-10}$ and T3SS-plant interactions ${ }^{11}$, the structural proteins of the injectisome are highly conserved $^{12,13}$. An extracellular needle is formed by helical polymerization of a T3SS-exported protein, and ends in a pentameric tip structure. At the proximal end, the needle is anchored by two multimeric membrane rings that span the outer and inner membrane. Additionally, the inner membrane (IM) ring encloses the export apparatus. At the cytosolic interface of the injectisomes, four soluble T3SS components (SctK/Q/L/N) interact to form six pod structures ${ }^{14,15}$ (Fig. 1a).

The soluble T3SS components SctK, SctQ, SctL, and SctN interact in a linear fashion ${ }^{16}$, and the presence of all four proteins is needed for their assembly at the injectisome, and subsequently for effector secretion ${ }^{17,18}$. SctK/Q/L form a high molecular weight complex that has been shown to bind chaperones and effectors ${ }^{19}$. Since the cytosolic components do not co-purify with the rest of the needle, their structural arrangement has only been revealed by recent in situ cryo-electron tomography ${ }^{14,15,20,21}$, which showed the formation of six pod structures at the cytosolic interface of the injectisome. The connection between these pod structures and the membrane rings is established by the cytosolic component SctK, which binds to SctD. In the presence of SctK, the cytosolic domains of $\mathrm{SctD}\left(\mathrm{SctD}_{\mathrm{C}}\right)$ rearrange and in the case of the Salmonella SPI-1 T3SS form six discrete patches of four $\operatorname{SctD}_{\mathrm{C}}$ each that interact with one SctK protein, which in turn connects to SctQ, SctL, and SctN ${ }^{15,22,23}$.

In addition to forming the injectisome-bound pod structures, the cytosolic components exist in a freely diffusing cytosolic state, with proteins exchanging between the two states ${ }^{24}$. In the cytosol,

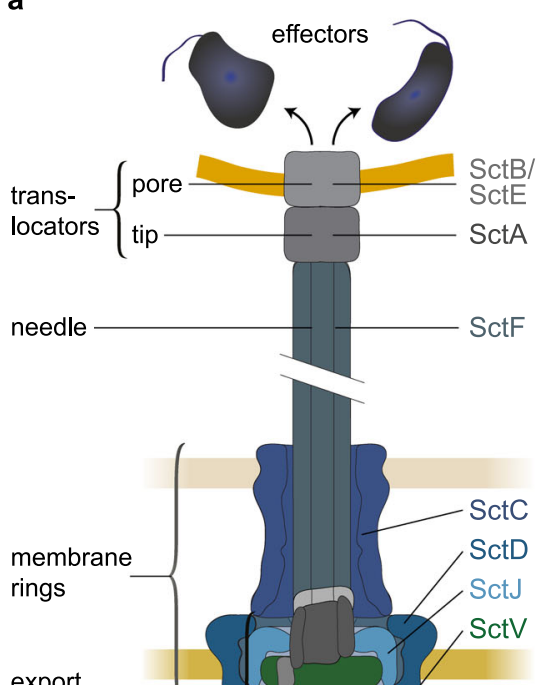

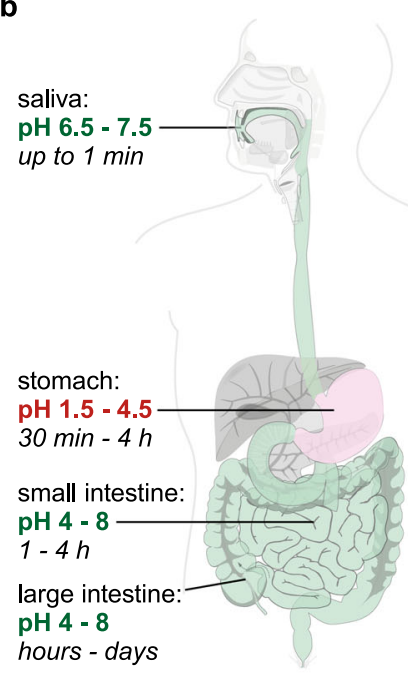

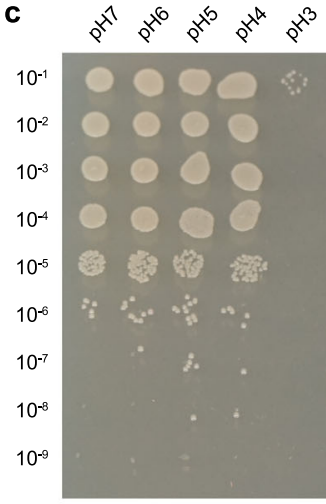

d

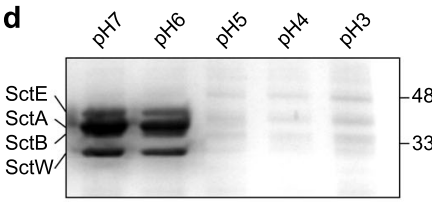

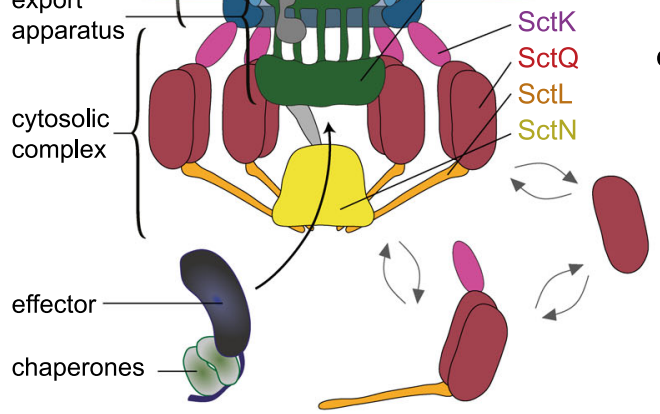

$$
\text { (1) }
$$

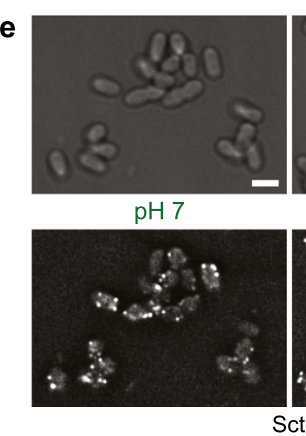

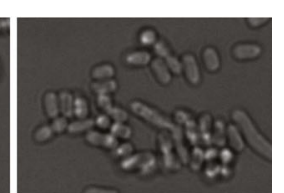

$\mathrm{pH} \mathrm{4,} 20 \mathrm{~min}$ $\mathrm{pH} \mathrm{4,60} \mathrm{min}$

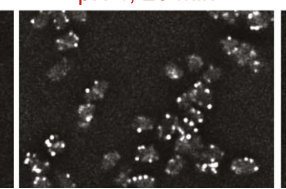

$\mathrm{SctF}_{\mathrm{cys}}+$ maleimide-CF 488A

Fig. 1 The Yersinia enterocolitica T3SS and its function and stability at low pH. a Schematic representation of the active T3SS injectisome (modified from ref. ${ }^{68}$ ). Left side, description of the main substructures; right side, names of T3SS components studied in this manuscript. Double arrows indicate the exchange of the cytosolic subunits or subcomplexes between the cytosolic and the injectisome-bound state. $\mathbf{b} \mathrm{pH}$ ranges and typical retention times at different parts of the gastrointestinal system ${ }^{43}, 44$. Digestive tract image based on the public domain template https://commons.wikimedia.org/wiki/File: Digestive_system_diagram_de.svg. c Dilution drop test of $Y$. enterocolitica cultures incubated at the indicated pH at $37^{\circ} \mathrm{C}$ for $30 \mathrm{~min}$. $\mathbf{d}$ In vitro secretion assay showing the export of native T3SS substrates (indicated on left side) in strain IML421asd at the indicated external pH values. Black and white scan of a coomassie-stained SDS-PAGE gel; supernatant of $3 \times 10^{8}$ bacteria per lane. Right side, molecular weight marker ( $\mathrm{kDa}$ ). Secretion assay of strain containing effectors, see Supplementary Fig. 3a. e Staining of T3SS needles at the different indicated external pH values; time indicates the duration of pH 4 treatment. A strain expressing the mutated needle subunit $\mathrm{SctF}_{55 \mathrm{c}}$ was covalently labeled with maleimide-CF $488 \mathrm{~A}$. Experiments for $\mathbf{c}$, $\mathbf{d}$, and $\mathbf{e}$ were performed at least 3 times with comparable results. Scale bar, $2 \mu \mathrm{m}$. 
$\mathrm{SctK} / \mathrm{Q} / \mathrm{L} / \mathrm{N}$ form a dynamic adaptive network, with a variety of complexes of different stoichiometries that change their composition in response to different external conditions ${ }^{18,25}$. Strikingly, protein interactions and exchange rates amongst the cytosolic components correlate with the activity of the injectisome ${ }^{18,24,26}$. However, the precise role of the cytosolic components in the secretion process remains unclear to this date.

Yersinia enterocolitica is an extracellular gastrointestinal pathogen that employs its T3SS to downregulate immune responses and prevent inflammation after the penetration of the intestinal epithelium. For initial attachment to the epithelium, the bacteria employ a number of adhesins ${ }^{27,28}$. The two major adhesion factors at the early stage of infection are the autotransporters invasin (inv), which is already expressed at ambient temperatures ${ }^{29,30}$ and Yersinia adhesin A (YadA) ${ }^{31}$; inv yadA double mutants are completely avirulent ${ }^{28,32}$. YadA is a key factor for establishing an infection ${ }^{33}$, which interacts with a variety of extracellular matrix molecules, including collagen and fibronectin ${ }^{34}$. YadA establishes close contact to the host cells enabling injection; its length is tightly linked to the length of the injection needle of the T3SS ${ }^{35}$. Y. enterocolitica is usually taken up with contaminated food or water. The shift from environmental to host temperature $\left(37^{\circ} \mathrm{C}\right)$ induces expression and assembly of the injectisomes as well as $\mathrm{YadA}^{36,37}$. The bacteria then have to pass the acidic environment of the stomach. During that time, the injectisome can already be present and ready for secretion of translocators (which form a pore in the host membrane and its connection to the needle, Fig. 1a) and effectors. Since the T3SS readily translocates cargo into any host cell type it adheres to, including immune cells, epithelial cells, and even red blood cells $^{38-42}$, a distinct mechanism is needed to prevent premature activation of the T3SS during the passage of low $\mathrm{pH}$ parts of the gastrointestinal system, such as the stomach (external $\mathrm{pH}$ of $1.5-4.5^{43,44}$, Fig. 1b), which would result in a loss of valuable resources, or even elicit immune responses.

We hypothesized that acidic environment may be detected by bacteria to inhibit effector secretion under these conditions. Here, we investigated this hypothesis with a combination of fluorescence microscopy, single-particle tracking, and functional assays. Our findings show that although parts of the T3SS, including the extracellular needle, are stable at low $\mathrm{pH}$, a set of cytosolic T3SS components temporarily unbind from the injectisome at low external $\mathrm{pH}$. The reversible dissociation corresponds to a temporary suppression of effector secretion by the T3SS. This mechanism prevents premature activation of the T3SS, while ensuring the reactivation of the T3SS, once a pH-neutral environment is reached. Our data provide a striking example for how bacteria apply protein dynamics to adapt the function of a large macromolecular machine essential for virulence to external conditions.

\section{Results}

Resistance of $Y$. enterocolitica and its T3SS needles to low external $\mathbf{p H}$. To investigate to which degree $Y$. enterocolitica can withstand a drop in external $\mathrm{pH}, \mathrm{Y}$. enterocolitica cultures in the exponential growth phase were exposed to different $\mathrm{pH}$ for 30 min at $37^{\circ} \mathrm{C}$. A subsequent dilution series on neutral $\mathrm{pH}$ agar showed high survival down to $\mathrm{pH} 4$ (Fig. 1c). Similarly, while the optical density of bacterial cultures slightly decreased over $90 \mathrm{~min}$ at $\mathrm{pH} 4$ at $37^{\circ} \mathrm{C}$, growth recovered at a reduced rate upon restoration of neutral pH (Supplementary Fig. 1). Together, these results show that $Y$. enterocolitica tolerates temporary incubation down to $\mathrm{pH} 3$, with limited fitness decrease at $\mathrm{pH} 4$ and above. $Y$. enterocolitica adheres to host cells, other bacteria and abiotic surfaces by adhesins, most importantly the trimeric adhesin YadA and invasin $31,34,45$. We thus tested whether low $\mathrm{pH}$ prevents the binding of YadA to collagen and more generally, of $Y$. enterocolitica cells to surfaces. Binding could be established at low $\mathrm{pH}$ in both cases, albeit at a significantly reduced level (Supplementary Fig. 2, Supplementary Movies 1-2). These results suggest that to avoid protein translocation into non-host cells, secretion itself might be prevented at low $\mathrm{pH}$.

To test under which conditions Y. enterocolitica secretes T3SS substrates, we performed an in vitro secretion assay where $Y$. enterocolitica cells primed for secretion were subjected to secreting media in the range from $\mathrm{pH} 8$ to $\mathrm{pH} 4$. Indeed, we observed that secretion did not occur at low $\mathrm{pH}$ (Fig. 1d, Supplementary Fig. 3a). This lack of secretion is not due to lower protein synthesis at $\mathrm{pH} 4$ (Supplementary Fig. 3b), suggesting a specific mechanism to suppress secretion at low external $\mathrm{pH}$.

But how does Y. enterocolitica prevent secretion at low $\mathrm{pH}$ ? To determine if the absence of secretion is due to a complete disassembly of injectisomes at that $\mathrm{pH}$, we visualized the needles at different $\mathrm{pH}$ values and over time by labeling an introduced cysteine residue with a maleimide-linked dye $\mathrm{e}^{46}$. The needles were stable at pH 4 over continued time periods (Fig. 1e, Supplementary Fig. 4).

Taken together, $Y$. enterocolitica as well as its injectisome needles can withstand low external $\mathrm{pH}$ conditions, but still translocators and effectors are not secreted.

Association of the dynamic cytosolic T3SS components to the injectisome is temporarily suppressed at low external $\mathbf{p H}$. We have recently found that the cytosolic T3SS components (SctK/Q/ $\mathrm{L} / \mathrm{N}$ ) form a dynamic network, where protein exchange is connected to the function of the injectisome (Fig. 1a) ${ }^{18,24}$. Hence, we wondered whether these dynamic components could be involved in the inhibition of secretion at low $\mathrm{pH}$. To investigate this question, we performed flow-cell-based total internal reflection fluorescence (TIRF) microscopy with functional N-terminal fluorescent protein fusions of the cytosolic components, expressed at native levels: EGFP-SctK, EGFP-SctQ, EGFP-SctL, and EGFP-SctN (Fig. 1a) ${ }^{17,18}$. At neutral or near-neutral $\mathrm{pH}$, the cytosolic components localized in foci at the bacterial membrane, which represent their injectisome-bound state ${ }^{17}$. However, at an external $\mathrm{pH}$ of 4 , all cytosolic components lost this punctuate localization, and the proteins relocated to the cytosol (Fig. 2a-c). The relocation remained stable over time at low external $\mathrm{pH}$ (Supplementary Fig. 5). Strikingly, this phenomenon was reversible: upon exposure to neutral external $\mathrm{pH}$, the foci recovered within a few minutes (Fig. $2 \mathrm{a}-\mathrm{c}$ ). This effect was observed both under secreting and non-secreting conditions (Supplementary Fig. 6a), and was independent of the fluorophore or visualization tag that was used (Supplementary Fig. 6b). Notably, while the fluorescence of genetically encoded fluorophores such as EGFP is pH-dependent ${ }^{47,48}$, the observed effect is not caused by the reduction of overall fluorescence in the cytosol (Fig. 2c, Supplementary Fig. 7).

Dissociation and re-association of the cytosolic T3SS components in response to the external $\mathrm{pH}$ was reversible for several cycles (Supplementary Movie 3), and dissociation kinetics were similar under non-secreting and secreting conditions (presence of $5 \mathrm{mM} \mathrm{CaCl}_{2}$ and EGTA, respectively) (Supplementary Fig. 8). To quantify the kinetics of association and dissociation of SctQ, we monitored EGFP-SctQ foci in a microscopy flow cell after a $\mathrm{pH}$ change from 7 to 4 and vice versa. Foci gradually disappeared within 2 min under secreting conditions (Fig. 2d, Supplementary Fig. 9, Supplementary data 1, Supplementary Movie 4). Upon restoration of neutral external $\mathrm{pH}$, this phenotype was reversed 
a

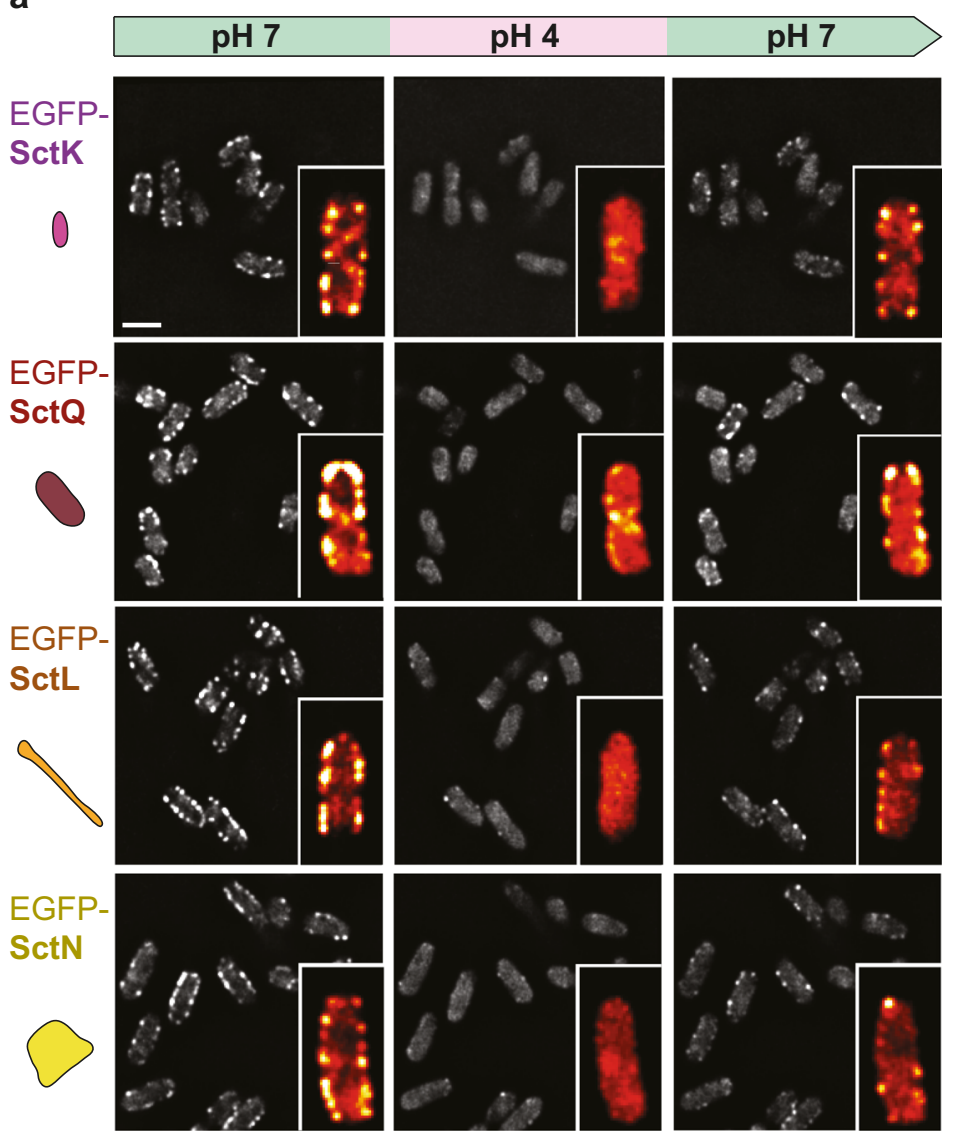

b Number of foci c Cytosolic fluorescence

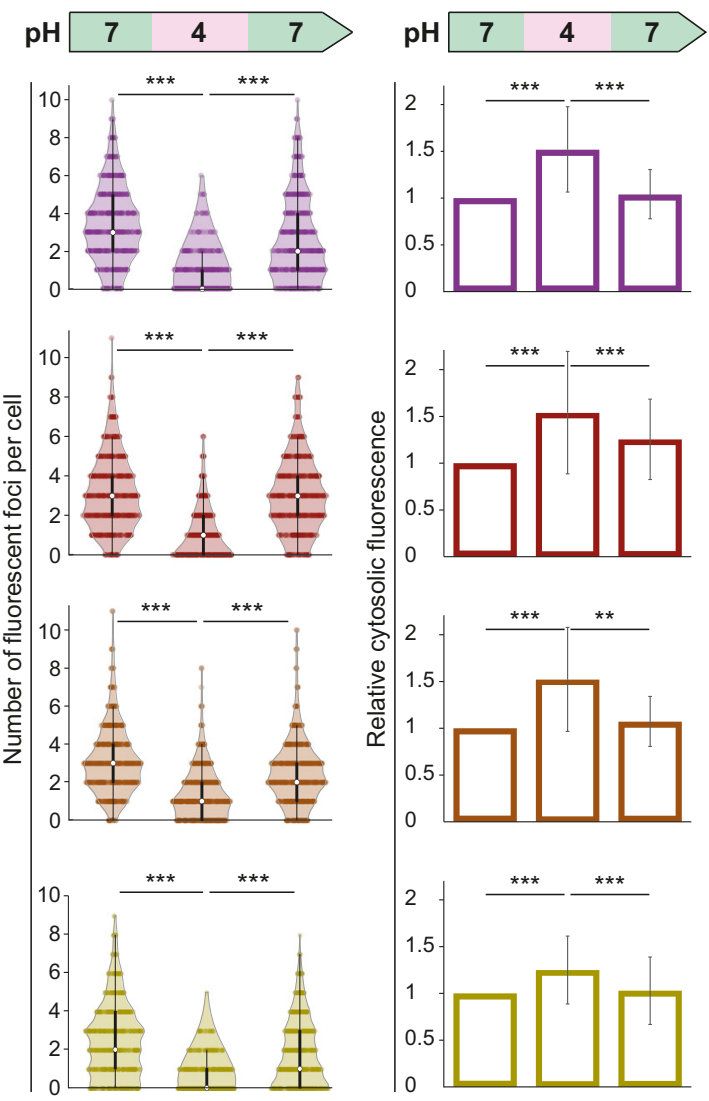

d

pH 7

pH 4

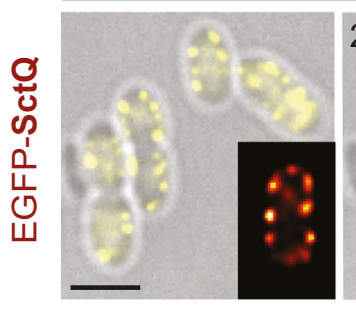

$20 \mathrm{~s}$

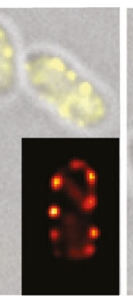

$50 \mathrm{~s}$

$100 \mathrm{~s}$

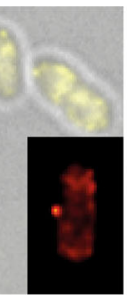

$160 \mathrm{~s}$

e

pH 7

pH 4

pH 7

composite $\mathrm{pH} 7$
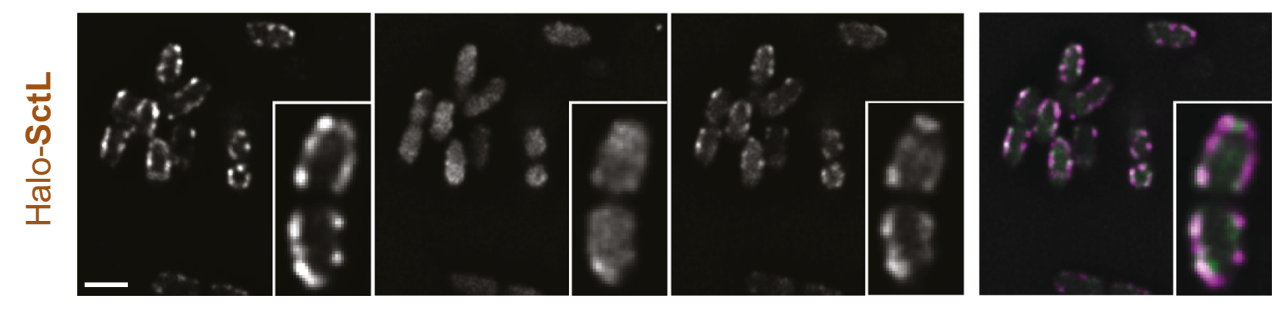

Fig. 2 The cytosolic T3SS components temporarily dissociate from the injectisome at low external pH. a Fluorescent micrographs of the indicated proteins in live $Y$. enterocolitica, consecutively subjected to different external pH in a flow cell. Images were taken under secreting conditions, 10 min after bacteria were subjected to the indicated $\mathrm{pH}$. Insets, enlarged single bacteria, visualized with the ImageJ red-hot color scale. b Quantification of foci per bacterium for the strains and conditions shown in (a). $n=453,792,466$, and 554 foci (from top to bottom) from three independent experiments. White circle denotes median, black bar denotes first and third quartile, black line denotes the lower/upper adjacent value. c Quantification of mean cytosolic fluorescence for the strains and conditions shown in (a). $n=75$ cells from three independent experiments per strain. Bars denote mean values. For $\mathbf{b}, \mathbf{c}$

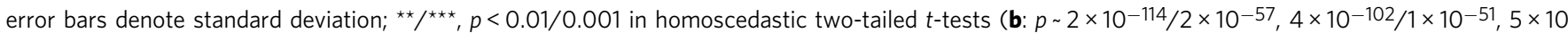
$-79 / 1 \times 10^{-69}, 8 \times 10^{-89} / 2 \times 10^{-51} ;$ c: $p \sim 8 \times 10^{-18} / 7 \times 10^{-13}, 5 \times 10^{-11} / 2 \times 10^{-3}, 2 \times 10^{-13} / 3 \times 10^{-9}, 6 \times 10^{-8} / 4 \times 10^{-4}$ for differences between pH for first/second pH 7 incubation, respectively, from top to bottom). d Kinetics of EGFP-SctQ dissociation after pH shift from 7 to 4 . Overlay of phase contrast (gray) and fluorescence images (yellow); insets, enlarged single bacterium, visualized with the ImageJ red-hot color scale. e Fluorescence micrographs of Halo-SctL, labeled with JF 646 prior to the first image, during consecutive incubation at different external pH as in (a). Right, overlay of fluorescence distribution at $\mathrm{pH} 7$ prior to and after $\mathrm{pH} 4$ incubation (magenta and green, respectively). Experiments for $\mathbf{a}$, d, and $\mathbf{e}$ were performed $>5,>5$, and 3 times, respectively, with comparable results. Scale bars, $2 \mu \mathrm{m}$. 
and foci were restored within a similar time range (Supplementary Fig. 9, Supplementary Fig. 10, Supplementary Movie 5).

To test whether the recovery of foci was due to the synthesis of new proteins or if the previously bound proteins rebind to the injectisomes, we covalently labeled the pool of Halo-tagged SctL with the Janelia Fluor JF 646 Halo ligand dye ${ }^{49}$ prior to the incubation at $\mathrm{pH} 4$ to ensure that only the protein pool present at the time of labeling was fluorescent. Similar to the previous experiments, we observed a reversible loss of fluorescent foci at the membrane and an increase in cytosolic signal at $\mathrm{pH} 4$ and rebinding of the fluorescent proteins upon changing $\mathrm{pH}$ to 7 (Fig. 2e). The cytosolic components colocalize with the needle at the initial pH 7 (Supplementary Fig. 11) and an overlay of the micrographs at $\mathrm{pH} 7$ before and after the incubation at $\mathrm{pH} 4$ indicated that most foci reform at the same position as they previously appeared (Fig. 2e, Supplementary Fig. 6b, Supplementary Fig. 11).

Taken together, our data indicate that the cytosolic components reversibly dissociate from the injectisome at low external $\mathrm{pH}$. Upon exposure to neutral $\mathrm{pH}$, proteins from the same pool rebind at the cytosolic interface of the injectisome, forming the potential basis for a regulatory mechanism for the prevention of secretion at low $\mathrm{pH}$.

Molecular mechanism of extracellular $\mathrm{pH}$ sensing. What is the molecular basis for the dissociation of the cytosolic T3SS components at low external $\mathrm{pH}$ ? To find out whether the $\mathrm{pH}$ is sensed intracellularly, we first tested the impact of the changed external $\mathrm{pH}$ on the cytosolic $\mathrm{pH}$, using a ratiometric $\mathrm{pHluorin}$ GFP variant ( $\mathrm{pHluorin} \mathrm{M} 153 \mathrm{R}^{50,51}$ ) as a $\mathrm{pH}$ sensor. Upon changing the external $\mathrm{pH}$ from 7 to 4 , the cytosolic $\mathrm{pH}$ dropped to a mildly acidic value ( $\mathrm{pH}$ 6.3-6.4). This cytosolic $\mathrm{pH}$ was retained for at least $30 \mathrm{~min}$ at external $\mathrm{pH} \mathrm{4}$, but quickly recovered upon re-establishment of neutral external pH (Fig. 3a).

To test if this mild drop in cytosolic $\mathrm{pH}$ directly causes the dissociation of the cytosolic complex, we treated bacteria with the proton ionophore 2,4-dinitrophenol, which attunes the cytosolic $\mathrm{pH}$ to the external $\mathrm{pH}^{52-54}$ (Supplementary Fig. 12), and visualized the localization of EGFP-SctQ at different $\mathrm{pH}$ values. EGFP-SctQ remained localized in foci representing assembled cytosolic complexes at $\mathrm{pH} 6.3$ and 6.0 (Fig. 3b), indicating that the observed disassembly of the cytosolic complex is not caused by the mild acidification of the cytosol.

Based on the above results, we searched for a periplasmic $\mathrm{pH}$ sensor. To this aim, we tested the effect of overexpression of the four candidate proteins that have periplasmic domains and influence the localization of the cytoplasmic components-SctC, SctD, SctJ, and SctV (Fig. 1a). We reasoned that if $\mathrm{pH}$-induced partial dissociation of one of these components induces the dissociation of the cytosolic complex, overexpression of this component would shift the equilibrium toward the associated form of the protein itself and, in consequence, decrease
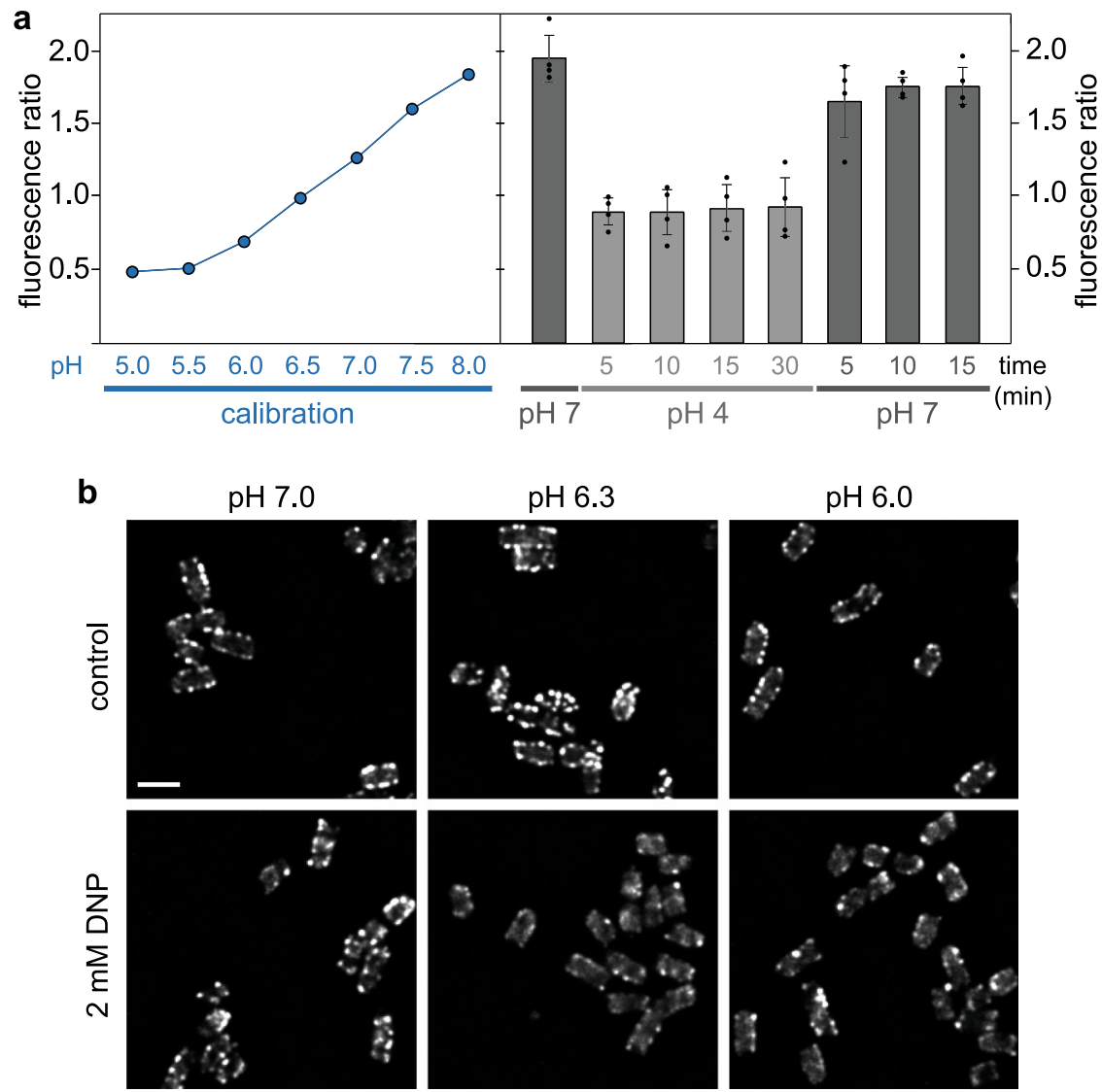

Fig. 3 Low external pH leads to a small drop in cytosolic pH, which does not induce the dissociation of cytosolic T3SS components. a Left, calibration of $\left(\mathrm{Ex}_{390 \mathrm{~nm}} / \mathrm{Ex}_{475 \mathrm{~nm}}\right)$ fluorescence ratio of purified pHluorin ${ }_{\mathrm{M} 153 \mathrm{R}}$ for the indicated $\mathrm{pH}$ values. Technical triplicate, error bars too small to display. Right, determination of cytosolic $\mathrm{pH}$ upon changing the external $\mathrm{pH}$ from 7 (first column) to 4 (columns 2-5) and back (columns 6-8). Fluorescence ratio $\left(\mathrm{Ex}_{390 \mathrm{~nm}} / \mathrm{Ex}_{475 \mathrm{~nm}}\right)$ of bacteria expressing cytosolic pHluorin ${ }_{\mathrm{M} 153 \mathrm{R}} . n=4$ independent experiments, single data points indicated by small circles. Bars denote mean values, error bars denote standard deviation. b Fluorescence distribution of EGFP-SctQ in live $Y$. enterocolitica at indicated external pH in absence (top) or presence (bottom) of the ionophore 2,4-dinitrophenol (DNP). The experiment was performed 3 times with comparable results. At pH 4.0, no foci are present. Scale bar, $2 \mu \mathrm{m}$. 

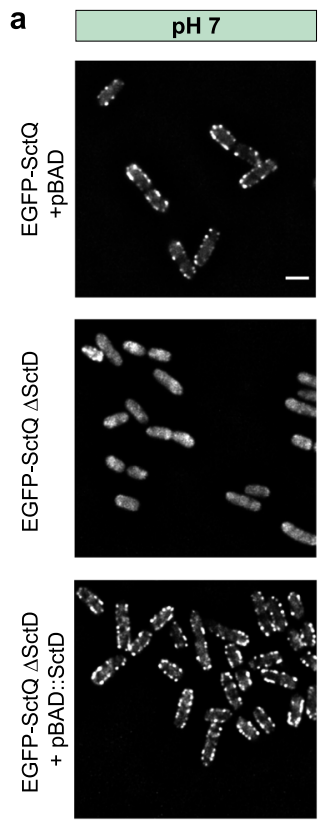
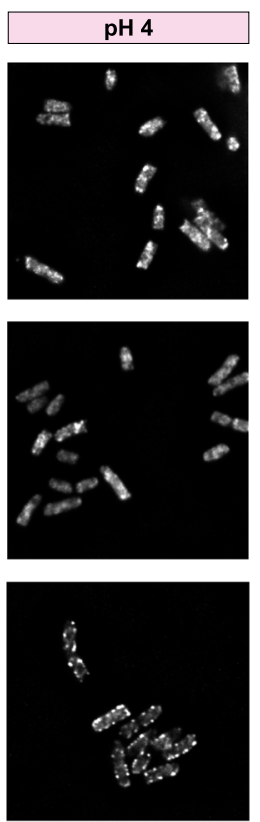

b

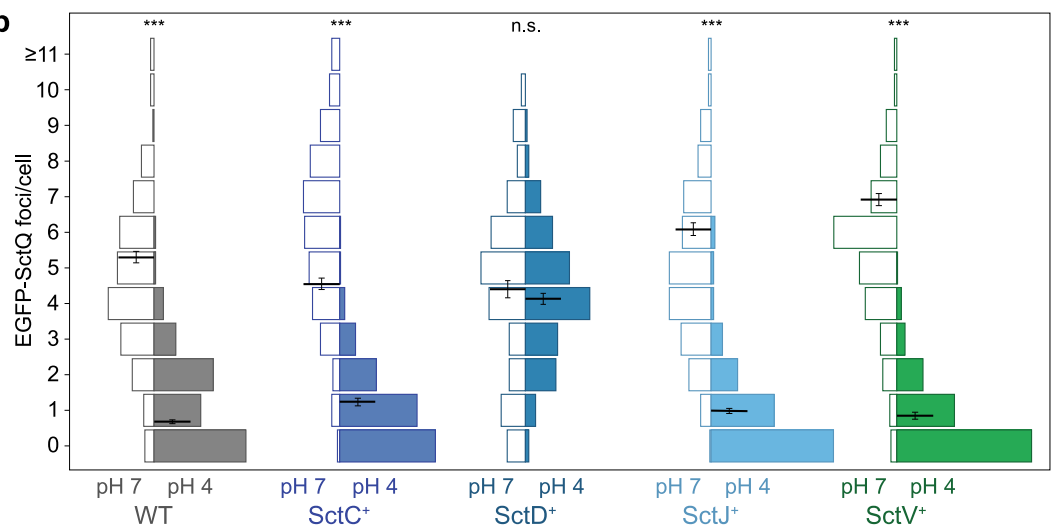

C

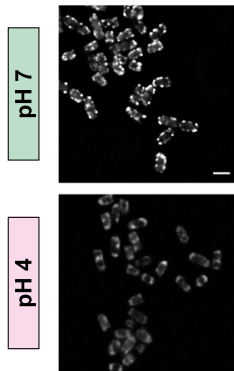

$\mathrm{SctC}^{+}$
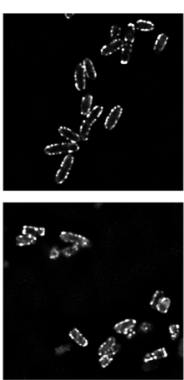

$\mathrm{SctD}^{+}$
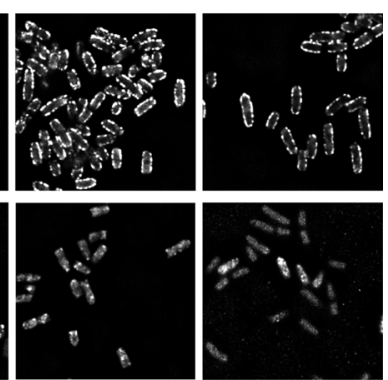

$\operatorname{Sct}^{+}$

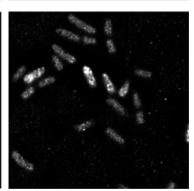

SctV ${ }^{+}$

Fig. 4 Overexpression of SctD, but not of SctC, SctJ or SctV suppresses the dissociation of the cytosolic components at low external pH. a Cellular localization of EGFP-SctQ in live Y. enterocolitica at the indicated external $\mathrm{pH}$. Top, wild-type; center, $\Delta \mathrm{SctD}$; bottom, additionally overexpressing SctD from plasmid. $n=3$ independent experiments. b Quantification of EGFP-SctQ foci per bacterium in wild-type EGFP-SctQ strain and strains overexpressing the indicated proteins (induced by $0.2 \%$ arabinose), at external pH 7 (left, open) and pH 4 (right, filled). Black lines and error bars indicate mean number of foci and standard error of the mean. The number of foci at $\mathrm{pH} 7$ and $\mathrm{pH} 4$ does not differ significantly in strains overexpressing SctD (n.s., $p=0.32$ in a homoscedastic two-tailed t-test), but in all other strains ( ${ }^{\star \star \star} p \sim 2 \times 10^{-126}, 3 \times 10^{-43}, 2 \times 10^{-112}, 3 \times 10^{-106}$ for WT and overexpression of SctC, SctJ, and SctV, respectively). Bars display fraction of cells; $n=199 / 310,203 / 149,115 / 137,205 / 279,178 / 184$ cells per strain and condition from 9/7, 8/10, 8/10, 9/9 8/9 fields of view ( $\mathrm{pH} 7 / \mathrm{pH} 4$ from left to right) from three independent experiments). c Cellular localization of EGFP-SctQ in the strains analyzed in (b). All tested strains show normal secretion, see Supplementary Fig. 14. Scale bars, $2 \mu \mathrm{m}$.

dissociation of the cytosolic components at low $\mathrm{pH}$. Indeed, overexpression of SctD strongly reduced the dissociation of the cytosolic component EGFP-SctQ at low external $\mathrm{pH}$ in an induction-dependent manner-while at wild-type SctD levels the number of EGFP-SctQ foci was strongly reduced at $\mathrm{pH} 4$, bacteria with increased levels of SctD retained a higher number of EGFPSctQ foci at pH 4 (Fig. 4, Supplementary Fig. 13a-c). In contrast, overexpression of SctC, SctJ or SctV did not interfere with $\mathrm{pH}$ induced dissociation of the cytosolic components (Fig. 4b, c, Supplementary Fig. 14). Taken together, these results strongly support a central role for SctD in the reaction to low external $\mathrm{pH}$.

SctD is a bitopic IM protein connecting the outer membrane $(\mathrm{OM})$ ring to the cytosolic components (Fig. 1a) ${ }^{15,55}$, that is an obvious candidate to act as a sensor for the external $\mathrm{pH}$. Earlier studies showed that lack of SctD, or its inability to bind to SctC, leads to a similar cytosolic location of SctK/L/N/Q as observed at an external pH of 4 (Fig. 2a $)^{17,18}$, and that the cytosolic domains of SctD connect to SctK via specific interactions (with four SctD binding to one SctK in Salmonella SPI-1) ${ }^{15,22,23}$. This suggests that structural rearrangements of SctD could lead to the dissociation of SctK and, subsequently, all other cytosolic components.

To investigate this hypothesis, we tested the behavior of SctD at low external pH by analyzing the localization of SctD. An EGFPSctD fusion is stable and shows a slightly reduced effector secretion (ref. ${ }^{24}$, Supplementary Fig. 15a, b). At pH 4, EGFPSctD foci in the membrane became less clearly defined than at $\mathrm{pH}$ 7 , with a concomitant increase in fluorescence throughout the membrane (Fig. 5a). In contrast to the cytosolic components, however, the SctD foci did not completely disappear, suggesting a reduced affinity at low external $\mathrm{pH}$. Importantly, like the cytosolic components, SctD recovered its localization in foci at neutral external $\mathrm{pH}$ within minutes (Fig. 5a). To study this unique phenotype in more detail, we performed single-molecule tracking of PAmCherry-SctD proteins in photoactivated localization microscopy (PALM). These experiments revealed that at an external $\mathrm{pH}$ of 7 , more than $90 \%$ of the SctD molecules in the IM were static (medium jump distance (mjd) of $0-60 \mathrm{~nm}$, corresponding to the measurement uncertainty ${ }^{56,57}$ ); by contrast, at an external pH of 4 , more than $40 \%$ of the SctD molecules became mobile within the membrane (Fig. 5b, Supplementary Fig. 16), indicating a dissociation from the core injectisome structure at low external pH. In line with these findings, the large T3SS export apparatus component SctV-EGFP retained its localization within foci at $\mathrm{pH} 4$; however, these foci (likely representing the SctV nonamers) became mobile within the membrane (Fig. 5c, Supplementary Fig. 17). The same behavior has been detected for SctV-EGFP in the absence of SctD ${ }^{58}$, supporting the notion that at an external $\mathrm{pH}$ of $4, \mathrm{SctV}$ is released from the SctD structure. To test whether the $\mathrm{N}$-terminal fluorophore tag influences the stability of the IM ring, we localized EGFP-SctQ, which depends on the presence of the IM ring for its localization ${ }^{17}$, at different external $\mathrm{pH}$. The fusion of mCherry to SctD did not influence the formation of EGFP-SctQ foci in any tested condition (Supplementary Fig. 15c), suggesting a labelingindependent effect of external $\mathrm{pH}$ on SctD assembly. 
a
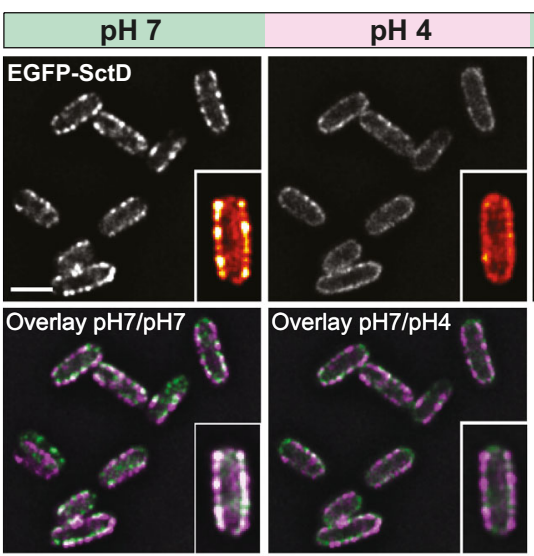

$\mathrm{pH} 7$

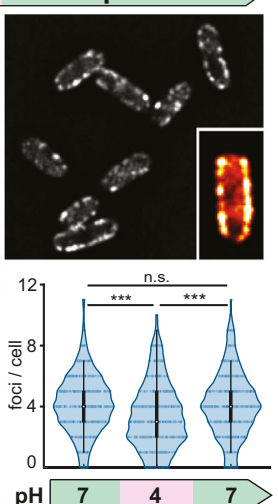

b
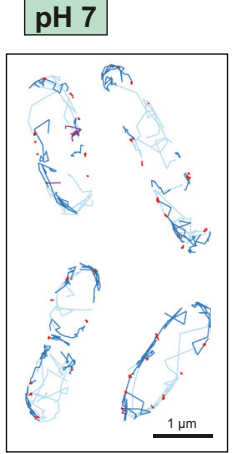

pH 4

C
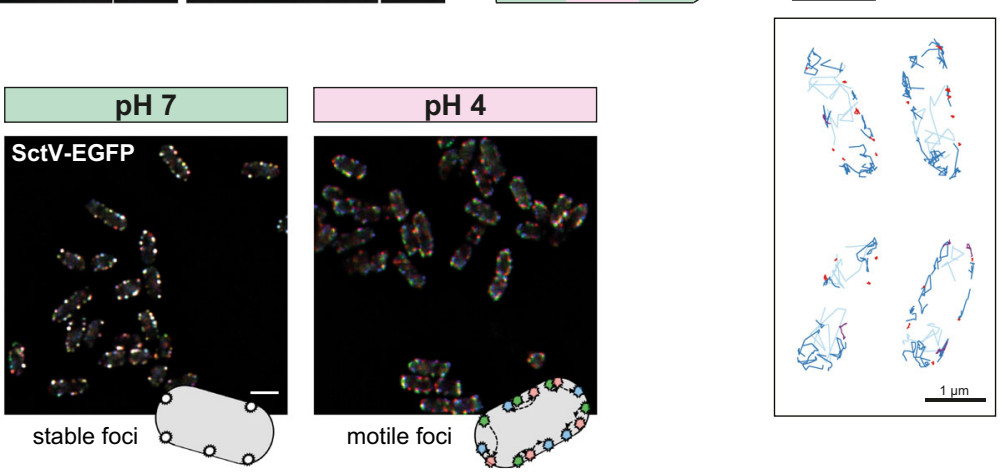
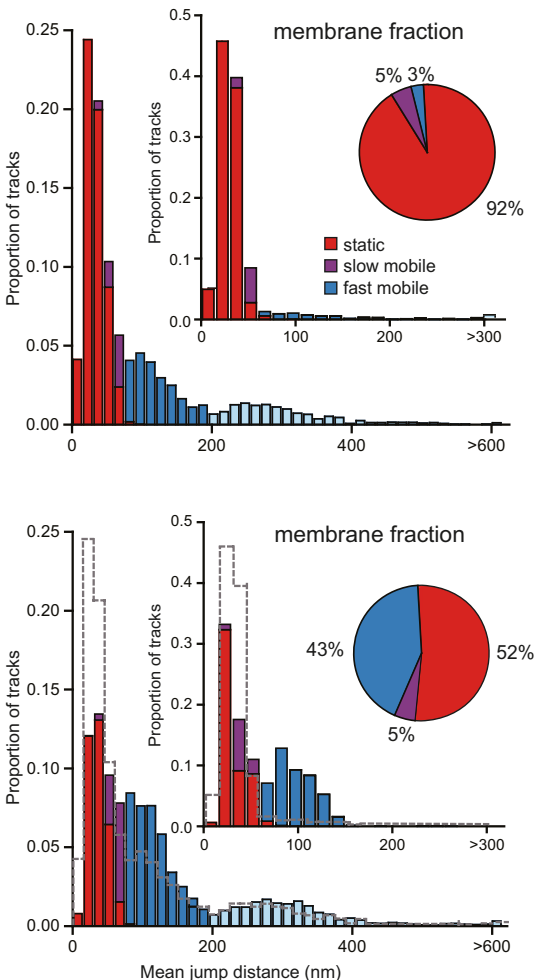

Fig. 5 The bitopic IM protein SctD reacts to low external pH. a Fluorescent micrographs of EGFP-SctD in live Y. enterocolitica, consecutively subjected to different external $\mathrm{pH}$ in a flow cell. Images were taken under secreting conditions, 10 min after bacteria were subjected to the indicated pH. Insets, enlarged single bacteria, visualized with the ImageJ red-hot color scale. Bottom, overlays of fluorescence at $\mathrm{pH} 7$ before $\mathrm{pH}$ change (magenta) and $\mathrm{pH} 7$ after $\mathrm{pH}$ change or $\mathrm{pH} 4$ (green). Bottom right, quantification of foci per bacterium. $n=468$ cells from three independent biological replicates. White circle denotes median, black bar denotes first and third quartile, black line denotes the lower/upper adjacent value. ${ }^{\star \star \star} p<0.001$ in homoscedastic two-tailed $t$-tests; n.s., difference not statistically significant $\left(p \sim 2 \times 10^{-11}, 2 \times 10^{-8}, 0.42\right.$ for $\mathrm{pH} 7 / 4, \mathrm{pH} 4 / 7$ and $\mathrm{pH} 7 / 7$, respectively). b PAmCherry-SctD dynamics in exemplary living $Y$. enterocolitica (left) and histograms (right) of the mean jump distances (MJD) of PAmCherry-SctD trajectories weighted by the number of jump distances used for calculating each MJD. Only trajectories with more than 6 one-frame jumps are shown and included into the analysis. Upper panel was measured at $\mathrm{pH}$ 7, lower panel at $\mathrm{pH}$ 4. Trajectories are assigned into two diffusive states: static (red) and mobile (violet and blue fractions) based on the experimental localization precision. Mobile trajectories are sorted into three MJD categories: lower than $60 \mathrm{~nm}$ (violet), lower than $195 \mathrm{~nm}$ (dark blue) and higher than $195 \mathrm{~nm}$ (light blue). Counts were normalized to the total number of trajectories. At pH 7 we acquired 29,859 trajectories (60\% static, 2\% mobile <60 nm MJD, 25\% mobile from 60 to $195 \mathrm{~nm}$ MJD, 13\% mobile >195 nm MJD; 19,473 membrane-bound trajectories). At pH 4 we acquired 33,036 trajectories (34\% static, 4\% mobile <60 nm MJD, 44\% mobile from 60 to $195 \mathrm{~nm}$ MJD, 18\% mobile >195 nm MJD; 21,600 membranebound trajectories). The bin size of $15 \mathrm{~nm}$ was calculated using the Freedman-Diaconis rule. Inset histograms and pie plot display statistics of only membrane-bound trajectories. The number of trajectories of membrane-bound static PAmCherry-SctD molecules decreases in $\mathrm{pH} 4$ (92\% to $52 \%$ ), while the number of diffusing PAmCherry-SctD with MJDs $<195 \mathrm{~nm}$ (dark blue bars) increases (3\% to 43\%). The fast fractions of PAmCherry-SctD molecules of MJDs $>195 \mathrm{~nm}$ (light blue), only visible for the whole-cell analysis, remain constant. Gray dashed lines in the pH 4 panels represent the outlines of the pH 7 analysis. c Spatial stability of SctV-EGFP foci over time at the indicated external $\mathrm{pH}$. Three images of the same focal plane were taken at $10 \mathrm{~s}$ intervals. Green/blue/red channel correspond to $t=0 / 10 / 20 \mathrm{~s}$. See Supplementary Fig. 17 for single time points and larger fields of view. The experiment was performed three times with similar results. Scale bars, $2 \mu \mathrm{m}$.

Physiological advantage of temporary suppression of type III secretion at low $\mathbf{p H}$. We reasoned that bacteria could benefit from the dissociation of the cytosolic T3SS components at low external $\mathrm{pH}$ to suppress secretion in the low $\mathrm{pH}$ parts of the gastrointestinal system, including the stomach, where $\mathrm{pH}$ values of 4 and below prevail, and where T3SS activation might lead to energy depletion or even elicit immune reactions. If this would be the case, bacteria with a similar infection route, but not bacteria that do not pass the gastrointestinal tract during normal infection, and therefore are not under evolutionary pressure to suppress T3SS activity at low $\mathrm{pH}$, would be expected to display the same $\mathrm{pH}$ dependence for the localization of cytosolic T3SS components. We therefore tested the localization of cytosolic components at low external $\mathrm{pH}$ in Shigella flexneri and Pseudomonas aeruginosa. S. flexneri is a gastrointestinal pathogen that uses an evolutionarily distant T3SS, but like Y. enterocolitica, needs to pass the stomach to invade the colonic and rectal epithelium. In contrast, the T3SS of Y. enterocolitica and P. aeruginosa are closely related ${ }^{59}$, but the infection strategies of the two species differ. $P$. aeruginosa is not a gastrointestinal pathogen and mainly enters the host body through wounds. $S$. flexneri GFP-SfSctN ${ }^{60}$ formed fewer and less distinct foci than $Y$. enterocolitica EGFP-YeSctQ and $P$. aeruginosa EGFP-PaSctQ (Supplementary Fig. 18), possibly due to the lower stoichiometry of SctN compared to SctQ. Most importantly, in agreement with the hypothesis that the dissociation of cytosolic components at low external $\mathrm{pH}$ is a conserved adaptation to the passage of low $\mathrm{pH}$ parts of the gastrointestinal system during a normal infection, the fraction of $S$. flexneri GFP-SfSctN with foci significantly decreased at $\mathrm{pH} 4$, whereas $P$. aeruginosa EGFP-PaSctQ cells showed a small, non-significant decrease (Fig. 6, Supplementary Fig. 18). 


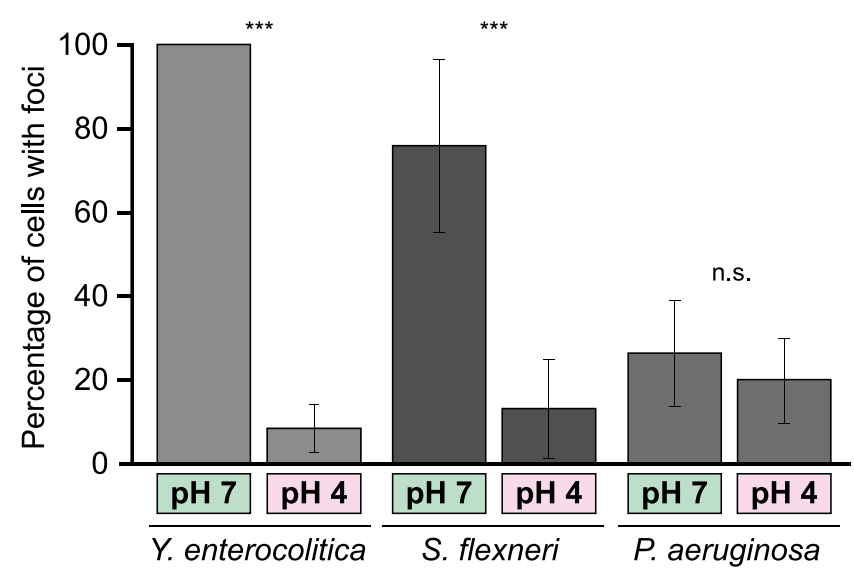

Fig. 6 The effect of external pH on the assembly of cytosolic T3SS components is species-specific. Percentage of bacteria with fluorescent foci at the indicated external $\mathrm{pH}$ for Yersinia enterocolitica EGFP-YeSctQ, Shigella flexneri GFP-SfSctN, and Pseudomonas aeruginosa EGFP-PaSctQ, respectively. $n=1134 / 1270,530 / 691,1078 / 926$ bacteria from 20, 22, 25 fields of view $(\mathrm{pH} 7 / \mathrm{pH} 4$ from left to right) from three independent experiments per condition. Bars denote mean values, error bars denote standard deviation between fields of view. n.s., difference not statistically significant; ${ }^{\star \star \star} p<0.001$ in a two-tailed homoscedastic $t$-test $\left(p \sim 2 \times 10^{-44}\right.$, $6 \times 10^{-16}, 0.053$, respectively).

To determine a potential molecular mechanism for this effect, we looked for amino acids in the periplasmic portions of the T3SS that can be protonated at $\mathrm{pH} 4$, but not at $\mathrm{pH} 7$ (Asp, Glu, His) in $Y$. enterocolitica and S. flexneri, but not in P. aeruginosa. As no such amino acids could be identified (Supplementary Table 1), we focused on protonatable amino acids that differ between $Y$. enterocolitica and $P$. aeruginosa (Supplementary Fig. 19). Single amino acid substitutions, as well as the combination of all four substitutions still led to dissociation of the cytosolic component SctQ, as well as a loss of secretion at $\mathrm{pH} 4$ (Supplementary Fig. 20). Notably, a $Y$. enterocolitica $\Delta$ SctD strain could be complemented for secretion by in trans expression of PaSctD, which showed the same expression level-dependent suppression of the dissociation of the cytosolic components at low external $\mathrm{pH}$ as YeSctD (Supplementary Fig. 13d-e). Taken together, these results and the clear effect of SctD overexpression (Fig. 4) suggest that the effect of the $\mathrm{pH}$ is conveyed by gradual rearrangement of intermolecular interactions rather than by discrete salt bridges.

In the more $\mathrm{pH}$-neutral intestine, $Y$. enterocolitica need to pass the $\mathrm{M}$ cells across the intestinal epithelium. Afterward, the injectisome must be ready to manipulate immune cells. To test whether the reversible dissociation of the cytosolic T3SS components supports a fast activation of the T3SS once back at neutral $\mathrm{pH}$, we monitored protein secretion over time after a temporary drop of external $\mathrm{pH}$ to 4 . We found that secretion was suppressed at low $\mathrm{pH}$, but restarted 20-40 min after reaching neutral $\mathrm{pH}$ (Fig. 7a). Notably, this recovery is much faster than the onset of effector secretion after de novo assembly of the T3SS by a temperature change to $37^{\circ} \mathrm{C}$ (Fig. 7a), supporting the notion that bacteria benefit from the temporary dissociation of the cytosolic subunits at low $\mathrm{pH}$ in two ways: This mechanism suppresses protein secretion at low external $\mathrm{pH}$, while ensuring a timely reactivation upon reaching a $\mathrm{pH}$-neutral environment (Fig. 7b).

\section{Discussion}

On their way through the gastrointestinal system, bacteria encounter a multitude of different $\mathrm{pH}$ environments. Importantly, the highly acidic stomach acts as natural barrier for food-borne infections. Gastrointestinal pathogens express factors that facilitate survival in these conditions, such as urease, of which high amounts are exported in Y. enterocolitica ${ }^{61-65}$. It was not known, however, if and how the activity of the T3SS, an essential virulence factor for many gastrointestinal pathogens, is regulated under these conditions. Although the T3SS target cells are downstream of the stomach for most gastrointestinal pathogens, cells in the low $\mathrm{pH}$ parts of the gastrointestinal system can be accessible and bacteria can attach to host cells at low $\mathrm{pH}$ (Supplementary Fig. 2, Supplementary Movies 1-2). Our data support the notion that bacteria prevent premature injection into host cells at this stage by directly using the external $\mathrm{pH}$ as a cue for the temporary suppression of the T3SS. While parts of the injectisome, including the needle, remain stable, the cytosolic components dissociate in an acidic environment ( $\mathrm{pH} 4$ and below). This effect persists at low external $\mathrm{pH}$; however, once the bacteria encounter neutral external $\mathrm{pH}$, both adherence via the adhesin YadA to collagen is significantly increased (Supplementary Fig. 2), and the binding of the cytosolic components is restored (Fig. 2). Bacteria conceivably benefit from this mechanism, which prevents premature effector translocation into any eukaryotic cells in contact in the acidic regions of the gastrointestinal tract, an event that would be energetically expensive and might elicit immune responses. Once the $\mathrm{pH}$-neutral intestine is reached, secretion is restarted within $20-40 \mathrm{~min}$, which is significantly faster than de novo synthesis of injectisomes at this time (Fig. 7). This is in line with earlier observations where assembly of injectisomes by fluorescence microscopy and the resulting secretion was only observed about $60 \mathrm{~min}$ after induction of T3SS assembly by temperature shift to $37^{\circ} \mathrm{C}^{17}$.

We found that similarly to $E$. coli ${ }^{66,67}, Y$. enterocolitica can partially compensate for acidic external environment, and that at an external $\mathrm{pH}$ of 4.0, the cytosolic $\mathrm{pH}$ remained at 6.3-6.4 (Fig. 3a). When we used a proton ionophore to create this cytosolic $\mathrm{pH}$ at a similar external $\mathrm{pH}$, the cytosolic T3SS components remained bound to the injectisome (Fig. 3b), suggesting that the external $\mathrm{pH}$ is not sensed in the bacterial cytosol. A central open question is how exactly the $\mathrm{pH}$ change is sensed in the extracytosolic space. We found that overexpression of SctD, which shifts the equilibrium toward association to the injectisome, strongly represses the $\mathrm{pH}$-dependent dissociation of the cytosolic components (Fig. 4). This is not the case for any of the other tested proteins with extracytosolic domains, SctC, SctJ or $\mathrm{SctV}$, pointing out SctD as the prime candidate for conveying the effect of low external pH. The bitopic IM component SctD could react to a drop in external $\mathrm{pH}$ with its periplasmic domain and then transmit this signal to the cytosol. Indeed, our data show that the localization of SctD within the membrane clearly differs between external $\mathrm{pH}$ of 7 and 4 (Fig. 5). Interestingly, SctD is one of the least conserved genes in the T3SS, especially in comparison to its direct structural neighbors, the highly conserved SctC secretin ring in the OM, as well as SctJ and the export apparatus proteins in the $\mathrm{IM}^{68}$. While this low sequence similarity impedes a multi-sequence alignment to identify conserved differences between the T3SS of gastrointestinal and non-gastrointestinal pathogens (Supplementary Table 1), except for the closely related $Y$. enterocolitica and $P$. aeruginosa (Supplementary Fig. 18b), it supports the notion that SctD is involved in species-specific adaptation of the T3SS, such as $\mathrm{pH}$ sensing. This hypothesis is further substantiated by the finding that in $P$. aeruginosa, which does not pass the gastrointestinal system during a normal infection, the effect of low $\mathrm{pH}$ is significantly restricted, with the majority of EGFP-SctQ foci remaining present at low external $\mathrm{pH}$ (Fig. 6). Mutation of candidate amino acids in YeSctD or even complementation of $Y$. enterocolitica $\Delta \mathrm{SctD}$ with $P a S c t D$ did not phenocopy the lack of $\mathrm{pH}$ sensitivity, suggesting that a broader 
a

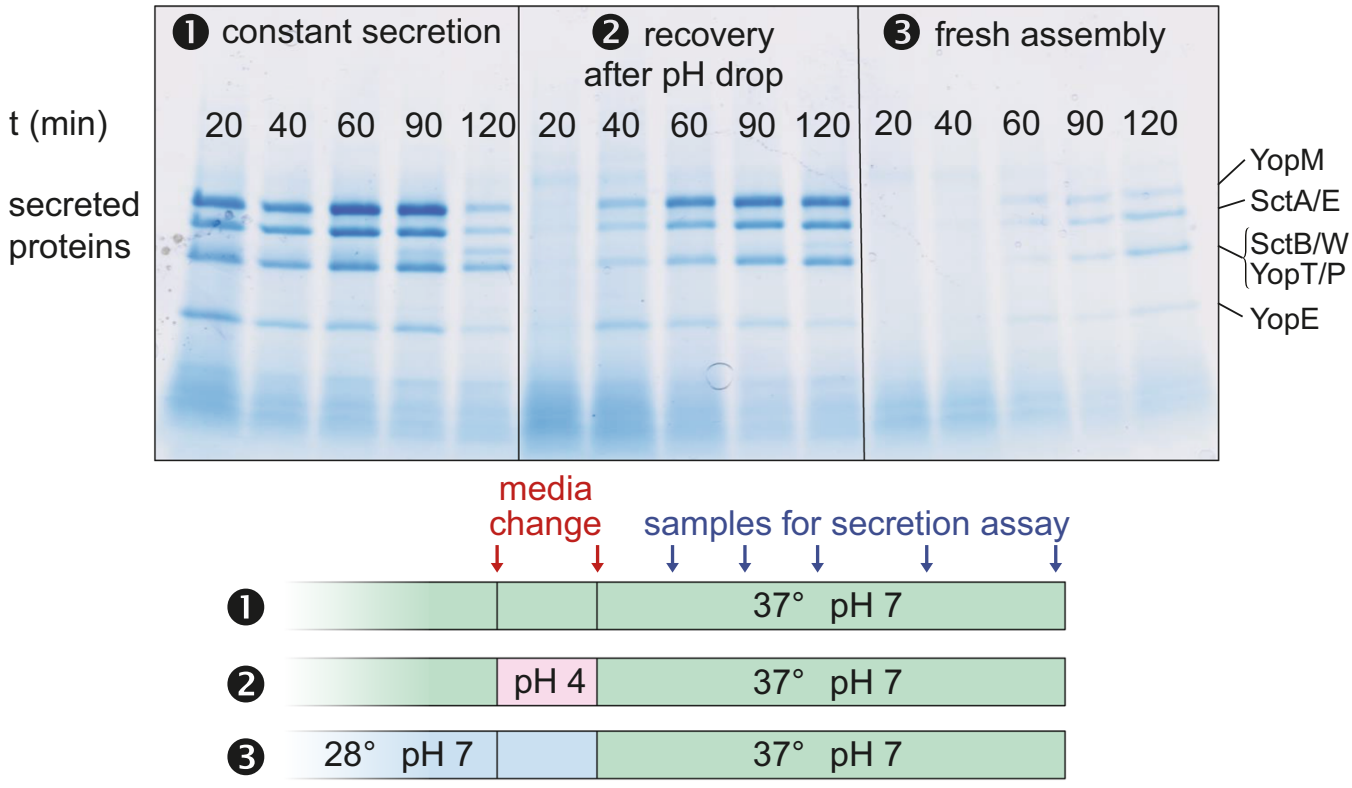

b

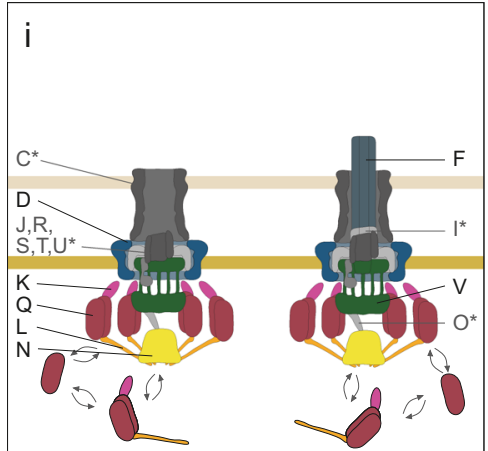

neutral $\mathrm{pH}$

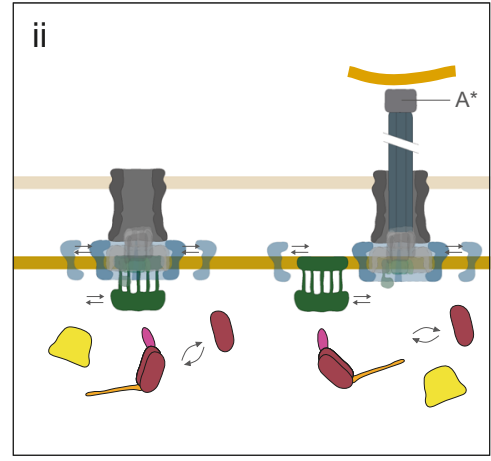

acidic $\mathrm{pH}$

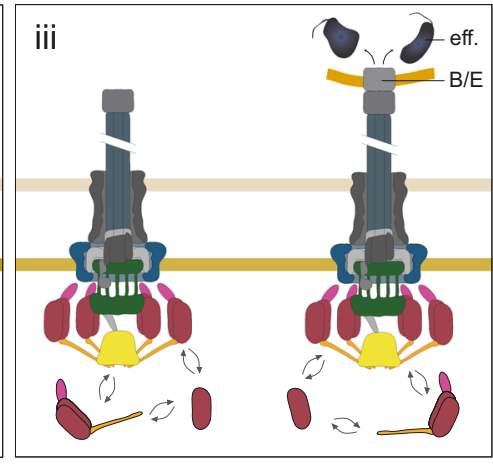

neutral $\mathrm{pH}$

Fig. 7 Temporary suppression of T3SS activity at low external pH enables a fast reactivation of secretion. a In vitro secretion assay showing the proteins exported by the T3SS in Y. enterocolitica MRS40 at the given time points after the second media change, (1) under constantly secretion-inducing conditions, (2) after a temporary change of the external $\mathrm{pH}$ to $4,(3)$ after incubation at $28^{\circ} \mathrm{C}$, where expression of injectisome components and effectors is downregulated and no injectisomes are assembled. Right side, exported effectors, based on ref. 104,105 . No molecular weight standard was loaded on this gel, please refer to Supplementary Fig. 3a for a direct comparison of molecular weight markers and exported effectors. $n=3$ independent experiments. $\mathbf{b}$ Model of the $\mathrm{pH}$-dependent suppression of T3SS activity. From left to right: (i) assembly of the T3SS upon entry into host organisms; cytosolic components bound and exchanging with cytosolic pool. (ii) Prevention of effector translocation upon host cell attachment in low pH environment, because cytosolic components are exclusively cytosolic. (iii) Re-association of cytosolic components to the injectisome and effector translocation upon host cell contact in neutral body parts. Letters represent protein identifiers (common Sct nomenclature); eff., effectors. Proteins whose localization was not specifically tested are indicated by asterisks and gray fill. Straight double arrows indicate diffusion in membrane; curved double arrows indicate the exchange of cytosolic subunits or subcomplexes between the cytosolic and the injectisome-bound state.

reversible conformational change at low $\mathrm{pH}$ is responsible for the observed effect. It is currently unclear at which interface(s) this effect takes place; however, the lack of phenotype of overexpression of the other T3SS components with periplasmic domains (SctC, SctJ, and SctV) makes the interface between neighboring SctD molecules the prime candidate for a $\mathrm{pH}$ dependent temporary dissociation.

Both possible types of $\mathrm{pH}$ sensing, direct structural change and rearrangement of intermolecular interactions, are used by biological systems: The E. coli membrane-integrated transcriptional regulator CadC senses acidic $\mathrm{pH}$ through direct protonation of a charged surface patch in its C-terminal periplasmic domain, and transduces the signal to the cytosol by its N-terminal cytosolic domain $^{69}$. Similarly, the P. syringae T3SS effector AvrPto transitions from a largely unfolded state in the mildly acidic bacterial cytosol to a well-defined fold in the neutral host cytosol $^{70}$. Perhaps most strikingly, the highly ordered multimeric structures of bacteriophages undergo large-scale structural changes at low $\mathrm{pH}$, that are reversible ${ }^{71-73}$. Our data show a reversible partial delocalization of SctD at low external $\mathrm{pH}$ (Fig. 5). The presence of SctD is required for binding of any cytosolic T3SS component ${ }^{17,18}$, most likely through a direct contact of four SctD to one SctK at the cytosolic interface of the $\mathrm{IM}^{15}$, indicating that this partial displacement of SctD (Fig. 5) is causal for the dissociation of the cytosolic T3SS components.

The dissociation and re-association kinetics of the cytosolic components of the T3SS revealed binding/unbinding half-times of about 1-2 min under secreting conditions (Fig. 2d, 
Supplementary Figs. 8-10, Supplementary Movies 4-5). These values are strikingly similar to the exchange rate of SctQ at the injectisome $\mathrm{e}^{24}$, suggesting that at low external $\mathrm{pH}$, primarily the re-association of the cytosolic components is prevented. Notably, recovery of fluorescent foci at $\mathrm{pH} 7$ appears to be faster and more pronounced for the proteins close to SctD (SctK and SctQ) compared to the more distant components (SctL and especially SctN) (Fig. 2); however, both visual and automated spot detection are influenced by the stoichiometry of the respective components, which makes comparisons across different parts of the T3SS difficult.

The mobile fraction of SctD at low external $\mathrm{pH}$ diffuses with a coefficient of $0.006-0.048 \mu \mathrm{m}^{2} / \mathrm{s}$, which is similar to other freely diffusing membrane proteins, including the unbound flagellar stator GFP-MotB ${ }^{74-77}$. This finding is compatible with passive diffusion of SctD in the IM under these conditions, which allows a rebinding within few seconds.

SctD is a core component of the injectisome basal body that is reliably copurified in purified needle complexes ${ }^{78,79}$ and has an early role in injectisome assembly ${ }^{68}$. While the dissociation of such a central protein upon external cues might be counterintuitive, dynamic exchange of structural components of large protein complexes and molecular machines has been shown in other cases, in particular for the flagellum (reviewed by Tusk et $\mathrm{al}^{80}$ ) and the DNA replisome $\mathrm{e}^{81}$, showing that structural and functional roles in a complex and protein exchange are not mutually exclusive.

While the effect of low external $\mathrm{pH}$ on the injectisome can be clearly observed in our experiments, it is difficult to estimate its role during infection. Activation of the T3SS by host cell contact can differ from activation by low calcium levels ${ }^{82}$ and the exposure of $Y$. enterocolitica to different $\mathrm{pH}$, as well as the extent of possible host cell contact in the low $\mathrm{pH}$ parts of the gastrointestinal system $^{83}$ are unclear. In particular, it remains to be determined whether invasin, whose regular downregulation at $37^{\circ} \mathrm{C}$ is prevented at acidic $\mathrm{pH}^{84}$ contributes to host cell binding under these conditions. Nevertheless, the described adaptation of T3SS function at low $\mathrm{pH}$ may explain the so-far enigmatic benefit of the dynamic exchange of the cytosolic parts of the injectisome during its function. Notably, the observed dissociation of the cytosolic proteins in response to low external $\mathrm{pH}$ may not reveal the complete mechanism for suppression of T3SS activity at this $\mathrm{pH}$. The observation that the dissociation of the cytosolic components occurs at a slightly lower $\mathrm{pH}$ (between 4 and 5) than the loss of effector secretion (which occurs between $\mathrm{pH} 5$ and 6), and that the re-initiation of secretion occurs later than the initial recovery of foci indicates that other factors might participate in this phenotype. The slightly delayed activation of secretion after restoration of neutral $\mathrm{pH}$ could also be explained by the time required for reassociating SctV to the machinery (the cytosolic components can already bind to the membrane rings in the absence of $\mathrm{SctV}^{17}$ ). Y. enterocolitica may in fact benefit from this lag, as it delays the antiphagocytic effects of the T3SS effectors, which otherwise may hamper the passage of $Y$. enterocolitica through the $M$ cells that is required to access the lymphoid follicles of the Peyer's patches ${ }^{85}$. As it is currently unclear to which extent $Y$. enterocolitica and other gastrointestinal pathogens directly contact cells in the low $\mathrm{pH}$ parts of the gastrointestinal system, including the stomach, this may be equally or even more beneficial for the bacteria than the direct suppression of secretion at low external $\mathrm{pH}$. Our finding that overexpression of SctD strongly reduces dissociation of the cytosolic T3SS components at low $\mathrm{pH}$, while retaining the secretion ability of $Y$. enterocolitica might be exploited in future infection experiments to investigate this question.

Like the $Y$. enterocolitica T3SS, the intracellular Salmonella enterica SPI-2 T3SS is strongly influenced by the external $\mathrm{pH}$; however, the mechanism described for SPI-2 differs from the one described in this study. Injectisome assembly and secretion of the translocon components in SPI-2 are activated by the low $\mathrm{pH}$ of the surrounding vacuole (around $\mathrm{pH} 5.0)^{86,87}$. After this step, neutral $\mathrm{pH}$, most likely indicative of a successfully established connection to the neutral host cytosol, leads to the disassembly of a gatekeeper complex, which in turn licenses the translocation of effectors ${ }^{87}$. Strikingly, a single amino acid exchange in the export apparatus protein SctV, V632D, governs this $\mathrm{pH}$-dependent effect $^{88}$. Both the sensory and the functional connection between the $\mathrm{pH}$ and T3SS activity differ between Salmonella SPI-2 and Y. enterocolitica, which highlights the high degree of functional adaptability of the T3SS.

In this study, we found that dynamic exchange of cytosolic components of the T3SS enables to suppress the activation of the T3SS at low external $\mathrm{pH}$ in Y. enterocolitica. Strikingly, this effect was also observed in $S$. flexneri, indicating a conservation in gastrointestinal pathogens, but not in $P$. aeruginosa, which does not pass low $\mathrm{pH}$ regions during normal infections. Our data highlight that not only the effector repertoire, but also dynamics and function of T3SS are adapted to the specific environment of the respective bacteria. This newly described pathway is a striking showcase for the variety and sophistication of mechanisms that allow bacteria to use different aspects of T3SS assembly and function, including protein dynamics, to tailor the activity of this essential virulence mechanism to their specific needs during infection.

\section{Methods}

Number of replicates and statistical analysis. The number of replicates is indicated with the data for all quantitative analyses. Where not indicated in cases where representative images are shown, experiments were performed for at least three independent biological replicates. A two-tailed homoscedastic $t$-test was used for statistical analysis. Unless specified differently, error bars display the standard deviation, except for discrete measurements of low numbers, such as the number of fluorescent foci per bacterium, where the standard error of the mean is displayed.

Bacterial strain generation and genetic constructs. A list of strains and plasmids used in this study can be found in Supplementary Table 2. The Y. enterocolitica strains used in this study are based on the $Y$. enterocolitica wild-type strain MRS40 ${ }^{89}$, and the strain IML421asd ( $\triangle$ HOPEMTasd), in which all major virulence effector proteins (YopH,O,P,E,M,T) are deleted ${ }^{90}$. Furthermore, this strain harbors a deletion of the aspartate-beta-semialdehyde dehydrogenase gene which render the strain auxotrophic for diaminopimelic acid (DAP).

Unless specifically mentioned otherwise, all Y. enterocolitica fusion proteins used in this study are expressed as endogenous fusions from their native location on the pYV virulence plasmid; the genes were introduced by allelic exchange ${ }^{91}$ and replace the respective wild-type genes.

For cloning and conjugation the E. coli strains Top10 and SM10 $\lambda$ pir were used, respectively. All constructs were confirmed by sequencing (Eurofins Scientific and Microsynth Seqlab). Constructs with single amino acid substitutions in SctD or SctF and other expression constructs were created by overlapping PCR using Phusion polymerase (New England Biolabs), and expressed from an arabinose controlled expression vector ( $\mathrm{pBAD})$.

Bacterial cultivation, in vitro secretion assays and fluorescence microscopy. $Y$ enterocolitica day cultures were inoculated from stationary overnight cultures to an $\mathrm{OD}_{600}$ of 0.15 and 0.12 for secreting and non-secreting conditions, respectively, in BHI medium (Supplementary Table 3 ) supplemented with nalidixic acid ( $35 \mathrm{mg} / \mathrm{ml}$ ), diaminopimelic acid $(80 \mathrm{mg} / \mathrm{ml})$, glycerol $(0.4 \%)$ and $\mathrm{MgCl}_{2}(20 \mathrm{mM})$. Where required, ampicillin was added $(0.2 \mathrm{mg} / \mathrm{ml})$ to select for $\mathrm{pBAD}$-based plasmids. For secreting conditions, cultures were additionally supplemented with $5 \mathrm{mM}$ EGTA; for non-secreting conditions, cultures were additionally supplemented with $5 \mathrm{mM} \mathrm{CaCl}_{2}$ and filtered through a $0.45 \mu \mathrm{m}$ filter. Cultures were incubated at $28^{\circ} \mathrm{C}$ for $90 \mathrm{~min}$. At this time point, expression of the yop regulon was induced by a rapid temperature shift to $37^{\circ} \mathrm{C}$ in a water bath and expression of proteins in trans was induced by the addition of $0.2-1.0 \%$ arabinose, as indicated.

For protein secretion or total cell analysis, bacteria were incubated at $37^{\circ} \mathrm{C}$ between 1 and $3 \mathrm{~h}$, as indicated. $2 \mathrm{ml}$ of the culture were collected at $21,000 \times g$ for $10 \mathrm{~min}$. The supernatant was separated from the total cell fraction and precipitated with trichloroacetic acid (TCA) for $1-8 \mathrm{~h}$ at $4{ }^{\circ} \mathrm{C}$; proteins were collected by centrifugation for $15-20 \mathrm{~min}$ at $21,000 \times g$ and $4^{\circ} \mathrm{C}$, washed once with ice cold acetone and then resuspended and normalized in SDS-PAGE loading buffer. Total 
cell samples were normalized to $2.5 \times 10^{8}$ bacteria and supernatant samples to the equivalent of $3 \times 10^{8}$ bacteria per SDS-PAGE gel lane. Samples were incubated for $5 \mathrm{~min}$ at $99^{\circ} \mathrm{C}$, separated on $12-20 \%$ SDS-PAGE gels, using BlueClassic Prestained Marker (Jena Biosciences) as size standard, and stained with InstantBlue (Expedeon). Immunoblots were carried out using a primary rabbit antibody against Y. enterocolitica SctD (MIPA232, 1:1000) in combination with a secondary antibody goat anti-rabbit, conjugated to horseradish peroxidase (Sigma A8275, 1:5000), and visualized using ECL chemiluminescent substrate (Pierce) on a LAS4000 Luminescence Image Analyzer. Uncropped and unprocessed scans of all gels and blots are available in the Source data file.

For fluorescence microscopy, bacteria were treated as described above. After $2-3 \mathrm{~h}$ at $37^{\circ} \mathrm{C}, 400 \mu \mathrm{l}$ of bacterial culture were collected by centrifugation $(2400 \times g$, $2 \mathrm{~min}$ ) and resuspended in $200 \mu \mathrm{l}$ microscopy minimal medium (Supplementary Table 3). Cells were spotted on $1.5 \%$ low melting agarose pads (Sigma) in microscopy minimal medium in glass depression slides. Where required, $80 \mathrm{mg} / \mathrm{ml}$ DAP for IML421asd ( $\triangle$ HOPEMTasd)-based strains, L-arabinose for induction of in trans expression, $5 \mathrm{mM} \mathrm{Ca}^{2+}$ for non-secreting conditions, or $5 \mathrm{mM}$ EGTA for secreting conditions were added.

For the fluorescence microscopy experiment comparing different bacterial species, Y. enterocolitica were treated as above, except for the final resuspension for microscopy, which was done in BHI supplemented with $50 \mathrm{mM}$ glycine, $50 \mathrm{mM}$ MES, $50 \mathrm{mM}$ HEPES, $80 \mathrm{mg} / \mathrm{ml}$ DAP, and $5 \mathrm{mM}$ EGTA and adjusted to the indicated $\mathrm{pH}$ for all species. P. aeruginosa overnight cultures were grown at $28{ }^{\circ} \mathrm{C}$. BHI medium (Supplementary Table 3) was supplemented with $20 \mathrm{mM} \mathrm{MgCl}_{2}, 200$ $\mathrm{mM} \mathrm{NaCl}$, and $5 \mathrm{mM}$ EGTA and inoculated to an $\mathrm{OD}_{600}$ of 0.15 and incubated for $2 \mathrm{~h}$ at $37^{\circ} \mathrm{C}$. This culture was then used to inoculate a fresh culture containing the same supplements to an $\mathrm{OD}_{600}$ of 0.15 . After $2 \mathrm{~h}$, bacteria were collected and prepared for microscopy as described above for Y. enterocolitica. S. flexneri overnight cultures where inoculated from a fresh LB-agar plate or glycerol stocks into BHI broth supplemented with ampicillin $(0.1 \mathrm{mg} / \mathrm{ml})$ and kanamycin $(0.05$ $\mathrm{mg} / \mathrm{ml})$. On the next day, fresh BHI cultures were inoculated to an OD of 0.12 and grown to an OD of around 1 at $37^{\circ} \mathrm{C}^{60}$. At this point, bacteria were collected and prepared for microscopy as described above for Y. enterocolitica. For the quantification of the fraction of T3SS-positive bacteria, 530-1143 bacteria in 21-25 fields of view from three independent experiments per strain and condition were classified independently by two blinded researchers and the average numbers were used for the graphs.

Wide field fluorescence microscopy. Microscopy was performed on a Deltavision Elite Optical Sectioning Microscope (Applied Precision), equipped with a UApo N $100 \times / 1.49$ oil TIRF UIS2 objective (Olympus) and a UPlanSApo $100 \times / 1.40$ oil objective (Olympus), using an Evolve EMCCD Camera (Photometrics). Samples were illuminated for $0.1 \mathrm{~s}$ with a $488 \mathrm{~nm}$ laser with a TIRF depth setting of 3440 (TIRF) or for $0.2 \mathrm{~s}$ with green LED light (standard oil objective). Excitation and emission filter sets used were 475/28 and 525/48 nm (green), 575/25 and 625/45 $\mathrm{nm}$ (red), or 632/22 and 679/34 nm (Cy5). The micrographs where deconvolved using softWoRx 7.0.0 (standard "conservative" settings). Images were then further processed with Fiji (Image 1.51f/1.52i/1.52n). Where necessary, drift correction was performed with the StackReg Plugin (ref. ${ }^{92}$, distribution dated July 7, 2011). For figures, representative fields of view were selected, and brightness and contrast of the micrographs was adjusted identically within compared image sets.

Sample sizes and number of replicates for wide field microscopy and all other experiments were determined prior to the experiments, based on experimental feasibility and their potential to draw clear conclusions. These numbers were not changed based on the experimental outcome.

Flow cell based TIRF microscopy. A microscopy flow cell was manufactured based on ref. ${ }^{93}$. Formation of injectisomes was induced under non-secreting conditions. After formation of the injectisomes $\left(150-180 \mathrm{~min}\right.$ at $\left.37^{\circ} \mathrm{C}\right)$, bacteria were collected and resuspended in $\sim 0.5$ volumes of microscopy medium (Supplementary Table 3) supplemented with $80 \mathrm{mg} / \mathrm{ml}$ DAP and $5 \mathrm{mM}$ EGTA. The flow cell was pre-incubated with microscopy medium and a bottom coverslip (25 $\mathrm{mm}$ No. 1.5; VWR) was attached to the cell. Bacteria were spotted on the coverslip and incubated for $1 \mathrm{~min}$ to allow attachment to the glass surface. The coverslip was covered with $60 \mu \mathrm{l}$ of the minimal medium and sealed from the top with an additional coverslip. The flow cell was mounted on the microscopy stage and gravity-driven buffer flow in the chamber was induced using a $1 \mathrm{ml}$ syringe. To exchange the buffer in the flow cell, the tube was quickly relocated to a new reservoir. Complete buffer exchange in the flow cell was determined to take $39 \pm 5 \mathrm{~s}$ $(n=7)$.

Detection and quantification of fluorescent foci. Detection and quantification of foci was performed by first segmenting the images using the software BiofilmQ ${ }^{94}$. After segmentation, fluorescent foci were detected using a customized script within BiofilmQ v0.1.3. Foci were identified by finding local maxima within the bacterial cells prior to filtering by their quality, which was defined to be their brightness above the cell's background intensity given by subtracting a smoothed image, divided by the overall mean fluorescence intensity of bacterial cells.
Quantification of fluorescent foci upon change of external pH. Bacteria were prepared for microscopy under secreting conditions as described above. After $2.5 \mathrm{~h}$ at $37^{\circ} \mathrm{C}$, bacteria were loaded into the flow cell and buffer exchange from $\mathrm{pH} 7$ to $\mathrm{pH} 4$ and vice versa was performed. Cells were tracked by TIRF microscopy. Micrographs were acquired every $10 \mathrm{~s}$ and quantification of foci was performed with BiofilmQ as described above.

Maleimide based needle staining. To visualize the injectisome needles, expression of $\mathrm{SctF}_{\mathrm{SSC}^{4}}{ }^{46}$ was induced from plasmid. Protein expression was induced with $0.4-1.0 \% \mathrm{~L}$-arabinose at the temperature shift. After $2-3 \mathrm{~h}$, bacteria were collected and resuspended in 0.2 volumes of microscopy medium supplemented with $5 \mu \mathrm{M}$ of CF 488A/568/633 maleimide dye (Sigma-Aldrich, USA) for $5 \mathrm{~min}$ in $100 \mu \mathrm{l}$ of minimal medium at $37^{\circ} \mathrm{C}$. After staining, cells were washed once with $500-1500 \mu$ l of minimal medium and spotted on $1.5 \%$ agarose pads in the same medium or analyzed in a flow cell as described above.

Halo staining with Janelia fluorescent dyes. To stain and visualize a defined pool of T3SS proteins, Halo-labeled proteins were visualized using Janelia Fluor 549NHS ester or Janelia Fluor 646-NHS ester. $500 \mu \mathrm{l}$ of bacterial culture were collected by centrifugation $(2400 \times g, 2 \mathrm{~min})$ and resuspended in $100 \mu \mathrm{lmicroscopy}$ medium. Bacteria were stained with $0.2 \mu \mathrm{M}$ Janelia Fluor JF $646 / \mathrm{JF} 549$ dyes at $37^{\circ} \mathrm{C}$ for 30 $\mathrm{min}$ in a tabletop shaker. Afterward, bacteria were washed twice in $500 \mu \mathrm{l} \mathrm{minima}$ medium and then visualized in a flow cell or on $1.5 \%$ agarose pads in the same medium.

Equilibration of cytosolic and external pH. 2,4-dinitrophenol (DNP) was diluted in methanol and used at a final concentration of $2 \mathrm{mM}$ in microscopy minimal medium. Cells were grown as described above, and resuspended in DNP containing medium immediately before being spotted on $1.5 \%$ agarose pads in the same medium containing DNP.

Bacterial survival test. Wild-type $Y$. enterocolitica MRS40 were inoculated to an $\mathrm{OD}_{600}$ of 0.12 in non-secreting conditions and incubated for $1.5 \mathrm{~h}$ at $28^{\circ} \mathrm{C}$ to reach exponential growth phase. Cells were collected by centrifugation at $2400-3000 \times g$ for 2-5 min. The supernatant was discarded and the collected bacteria were resuspended in a range of $\mathrm{pH}$-adjusted media buffered with $50 \mathrm{mM}$ glycine, $50 \mathrm{mM}$ HEPES and $50 \mathrm{mM}$ MES. Cultures were then placed in a $37^{\circ} \mathrm{C}$ shaking water bath and incubated at the indicated $\mathrm{pH}$ for $30 \mathrm{~min}$. A dilution series in 1:10 steps was performed. $4 \mu \mathrm{l}$ of the bacterial dilution were plated on a LB agar plate supplemented with nalidixic acid $(35 \mathrm{mg} / \mathrm{ml})$. Droplets were dried for $15 \mathrm{~min}$ before incubation of the plate overnight at $28^{\circ} \mathrm{C}$.

Growth curve assays. Wild-type $Y$. enterocolitica MRS40 were inoculated to an $\mathrm{OD}_{600}$ of 0.12 in secreting conditions and incubated for $90 \mathrm{~min}$ at $28^{\circ} \mathrm{C}$. At this point, cells were collected by centrifugation $(2400 \times g, 2 \mathrm{~min})$, and resuspended in $37^{\circ} \mathrm{C}$ fresh pre-warmed secreting medium buffered with $50 \mathrm{mM}$ glycine, $50 \mathrm{mM}$ HEPES and adjusted to the indicated $\mathrm{pH}$. After $90 \mathrm{~min}$, one batch of cells incubated at $\mathrm{pH} 4$ were collected again and resuspended in fresh buffered secretion medium at $\mathrm{pH}$ 7. All strains were incubated for further $90 \mathrm{~min}$. During the experiment, the $\mathrm{OD}_{600}$ was measured every $30 \mathrm{~min}$ in technical duplicates, which were averaged; the figure displays the single data points for three independent biological replicates

pHluorin purification and calibration. The protocol described by Nakamura et al. ${ }^{95}$ was adapted for bench top purification. Expression of ratiometric GSTpHluorin $_{\mathrm{M} 153 \mathrm{R}}$ in E. coli DH5aZI was induced in a $500 \mathrm{ml}$ culture with $1 \mathrm{mM}$ IPTG, followed by $4 \mathrm{~h}$ incubation at $28^{\circ} \mathrm{C}$. Cells were harvested and stored for further processing at $-80^{\circ} \mathrm{C}$. Next, cells were thawed on ice, resuspended in lysis buffer and disrupted by two passages through a French Press. The lysate was centrifuged $\left(75,600 \times g, 60 \mathrm{~min}, 4^{\circ} \mathrm{C}\right)$ and the supernatant was gently mixed with the previously equilibrated glutathione agarose at $4{ }^{\circ} \mathrm{C}$ for $1.5 \mathrm{~h}$ in a small spinning wheel. The agarose was collected by centrifugation $(500 \times g, 5 \mathrm{~min})$ and washed with PBS three times. A thrombin digest was performed in $2 \mathrm{ml}$ PBS (16 units) while incubating at room temperature for $60 \mathrm{~min}$ on a roll mill. Agarose was removed by centrifugation $(500 \times g, 5 \mathrm{~min})$ and the protein was stored at $-80^{\circ} \mathrm{C}$ for further use.

The calibration was performed on a Deltavision Elite microscope. $5 \mu \mathrm{l}$ of purified pHluorin protein were spotted on a $\mathrm{KOH}$-cleaned microscopy slide in an enclosed compartment (Thermo Fisher Scientific GeneFrame, AB-0577) and incubated for $5 \mathrm{~min}$ to ensure attachment to the glass surface. Then, $10 \mu \mathrm{lof} \mathrm{pH}$ adjusted PBS buffered with $200 \mathrm{mM}$ glycine, $200 \mathrm{mM}$ HEPES, and $200 \mathrm{mM}$ MES were added. Ratiometric pHluorin fluorescence was determined using the DAPI excitation filter $(390 / 18 \mathrm{~nm})$ or GFP excitation filter $(475 / 28 \mathrm{~nm})$ at $32 \%$ illumination intensity, in combination with a GFP emission filter set $(525 / 48 \mathrm{~nm})$ with $0.3 \mathrm{~s}$ exposure time. The overall fluorescence of the images before deconvolution was determined and corrected for background fluorescence levels, which were measured with an empty slide filled with PBS. The ratio of fluorescence intensity using DAPI/Green vs. Green/Green excitation/emission filters was determined for a $\mathrm{pH}$ range from $\mathrm{pH} 8-\mathrm{pH} 5$ in $0.5 \mathrm{pH}$ steps. 
Single-particle tracking photoactivated localization microscopy (sptPALM).

Bacteria were cultivated under non-secreting conditions as described above. After $2.5 \mathrm{~h}$ of incubation at $37^{\circ} \mathrm{C}$, the media was changed to pre-warmed $\left(37^{\circ} \mathrm{C}\right)$ minimal microscopy medium containing the same supplements as the BHI before. Cells were incubated for $30 \mathrm{~min}$ and then washed four times in 5 volumes of prewarmed $\left(37^{\circ} \mathrm{C}\right) \mathrm{EZ}$ medium (Supplementary Table 3) supplemented with DAP and $5 \mathrm{mM} \mathrm{CaCl}$. Bacteria were concentrated $2 \times$ after the last wash and spotted on a $1.5 \%$ agarose pad in EZ medium supplemented with DAP and $5 \mathrm{mM} \mathrm{CaCl}_{2}$ on a $\mathrm{KOH}$-cleaned microscopy slide in an enclosed compartment (Thermo Fisher Scientific GeneFrame, AB-0577). Imaging was performed on a custom build setup based on an automated Nikon Ti Eclipse microscope equipped with appropriate dichroic and filters (ET DAPI/FITC/Cy3 dichroic, ZT405/488/561rpc rejection filter, ET610/75 bandpass, Chroma), and a CFI Apo TIRF 100x oil objective (NA 1.49, Nikon). All lasers ( $405 \mathrm{~nm}$ OBIS, $561 \mathrm{~nm}$ OBIS; all Coherent Inc. USA) were modulated via an acousto-optical tunable filter (AOTF) (Gooch and Housego, USA). Fluorescence was detected by an EMCCD camera (iXON Ultra 888, Andor, UK) in frame transfer mode and read-out parameter settings of EM-gain 300, preamp gain 2 and $30 \mathrm{MHz}$ read-out speed. The z-focus was controlled using a commercial perfect focus system (Nikon). Acquisitions were controlled by MicroManager v1.4.23 ${ }^{96}$. Live cell sptPALM experiments were performed on a customized heating stage at $25^{\circ} \mathrm{C}$. Live Y. enterocolitica PAmCherry-SctD cells were imaged in HILO illumination mode ${ }^{97}$. Applied laser intensities measured after objective were $35 \mathrm{~W} / \mathrm{cm}^{2}(405 \mathrm{~nm})$ and $800 \mathrm{~W} / \mathrm{cm}^{2}(561 \mathrm{~nm})$. Prior to recording each new region of interest (ROI), a pre-bleaching step of $561 \mathrm{~nm}$ illumination was applied for $30 \mathrm{~s}$ to reduce autofluorescence. Videos were then recorded for 2000 frames pulsing the $405 \mathrm{~nm}$ laser every 20th imaging frame at $5 \mathrm{~Hz}$ with an exposure time of $200 \mathrm{~ms}$ per frame. After sptPALM imaging, a bright light snapshot of all illuminated regions was recorded to obtain the bacterial cell shapes.

Single molecule localizations were obtained using rapidSTORM 3.3.198 and single cells were manually segmented in Fiji (Image $1.51 \mathrm{f} / 1.52 \mathrm{i} / 1.52 \mathrm{n})^{99}$. sptPALM data were tracked, visualized and filtered using the swift tracking software 0.3.1. Trajectories were allowed to have a maximum of 5 frames of gap time (e.g., caused by fluorophore blinking). Trajectories were assigned to their diffusive states (static and mobile) on the basis of the experimental localization precision of about $25 \mathrm{~nm}$ (determined by the NeNA method ${ }^{100}$ ). For trajectories with more than 6 one-frame jumps, the mean jump distance (MJD) was calculated (jumps spanning several frames due to dark times were not used in MJD calculations). The obtained MJDs were weighted by the number of jumps and displayed in a histogram using OriginPro 9.4 (Origin LAB Corporation, USA). To estimate the diffusion coefficient D from the MJDs (M) at the frame rate $\tau=200 \mathrm{~ms}$ and the localization precision $\sigma_{\mathrm{m}}=25 \mathrm{~nm}$, the equation $\mathrm{D}=\mathrm{M}^{2} \pi^{-1}-\sigma_{\mathrm{m}}{ }^{2} \tau^{-1}$ was used.

Y. enterocolitica YadA and cellular adhesion assays. To measure YadA adhesion to collagen at different $\mathrm{pH}$ values, an ELISA-like binding assay was performed ${ }^{101-103}$. Clear 96 well plates (Sarstedt, Ref. 82.1581) were coated with $100 \mu \mathrm{l}$ of calf collagen type I $\left(10 \mu \mathrm{g} / \mathrm{ml}\right.$, ThermoFisher A1064401) in $\mathrm{H}_{2} \mathrm{O}$ with 0.01 $\mathrm{M}$ acetic acid for $1 \mathrm{~h}$ at room temperature (RT). The supernatant was discarded and the wells were blocked with $1 \%$ BSA in PBS and afterward washed three times with $0.1 \%$ BSA in PBS. Afterward, $100 \mu \mathrm{L}$ of purified YadA head domains with a Cterminal $\mathrm{His}_{6}$-tag at a concentration of $10 \mu \mathrm{g} / \mathrm{mL}$ were incubated in the wells. In order to test binding at different $\mathrm{pH}$, the YadA heads were diluted in acetic acid/ sodium acetate at $\mathrm{pH} 4.0$ or $\mathrm{pH} 5.0$ and in PBS for higher $\mathrm{pH}$ values. Binding was allowed for $1 \mathrm{~h}$ at RT. Afterward, the plate was emptied and washed three times with $0.1 \%$ BSA in PBS. The wells were blocked with $1.0 \%$ BSA in PBS for $1 \mathrm{~h}$ at RT. For detection, Ni-HRP conjugates (HisProbe-HRP, Thermo Fisher Scientific, Ref. 15165) were diluted in $0.1 \%$ BSA in PBS and $100 \mu \mathrm{l}$ per well were incubated for $1 \mathrm{~h}$ at RT. The Ni-HRP conjugate solution was discarded and the wells washed three times with PBS. Detection was performed using ABTS substrate (Thermo Scientific. Ref. 34026). Development was allowed for $30 \mathrm{~min}$. Absorption was measured at $405 \mathrm{~nm}$ on a plate reader (Biotek Synergy H1).

Glass binding assays for live $Y$. enterocolitica were performed in a flow cell. Bacteria were treated as mentioned above, resuspended in microscopy medium at the indicated $\mathrm{pH}$ value, and added to the flow cell as described above. Bacteria were tracked visually for $10 \mathrm{~min}$ afterward.

Reporting summary. Further information on research design is available in the Nature Research Reporting Summary linked to this article.

\section{Data availability}

All relevant data are included in the paper and/or its Supplementary information files. Source data are provided with this paper.

\section{Code availability}

Version 0.3.1, used in this manuscript, and all subsequent versions of the swift software, as well as documentation and test data sets, can be obtained on the swift beta-testing repository (http://bit.ly/swifttracking) and upon request to the authors.
Received: 27 March 2020; Accepted: 12 February 2021; Published online: 12 March 2021

\section{References}

1. Hueck, C. J. Type III protein secretion systems in bacterial pathogens of animals and plants. Microbiol. Mol. Biol. Rev. 62, 379-433 (1998).

2. Wagner, S. \& Diepold, A. A Unified Nomenclature for Injectisome-Type Type III Secretion Systems. in Current Topics in Microbiology and Immunology Vol. 427: 1-10, https://doi.org/10.1007/82_2020_210 (Springer, 2020).

3. Büttner, D. Protein export according to schedule: architecture, assembly, and regulation of type III secretion systems from plant- and animal-pathogenic bacteria. Microbiol. Mol. Biol. Rev. 76, 262-310 (2012).

4. Bastedo, D. P., Lo, T., Laflamme, B., Desveaux, D. \& Guttman, D. S. Diversity and evolution of type III secreted effectors: a case study of three families, 201-230, https://doi.org/10.1007/82_2019_165 (Springer, 2019)

5. Coburn, B. A., Sekirov, I. \& Finlay, B. B. Type III secretion systems and disease. Clin. Microbiol. Rev. 20, 535-549 (2007).

6. Pha, K. Yersinia type III effectors perturb host innate immune responses. World J. Biol. Chem. 7, 1 (2016).

7. de Jong, M. F. \& Alto, N. M. Cooperative immune suppression by Escherichia coli and Shigella effector proteins. Infect. Immun. 86, 1-10 (2018).

8. Johnson, R., Mylona, E. \& Frankel, G. Typhoidal Salmonella: distinctive virulence factors and pathogenesis. Cell. Microbiol. 20, 1-14 (2018).

9. Shenoy, A. R., Furniss, R. C. D., Goddard, P. J. \& Clements, A. Modulation of host cell processes by T3SS effectors. Curr. Top. Microbiol. Immunol. 416, 73-115 (2018)

10. De Souza Santos, M. \& Orth, K. The role of the type III secretion system in the intracellular lifestyle of enteric pathogens. Microbiol. Spectr. 7, https://doi.org/ 10.1128/microbiolspec.BAI-0008-2019 (2019).

11. Tampakaki, A.P. Commonalities and differences of T3SSs in rhizobia and plant pathogenic bacteria. Frontiers in plant science 5, p.114 (2014).

12. Deng, W. et al. Assembly, structure, function and regulation of type III secretion systems. Nat. Rev. Microbiol. 15, 323-337 (2017).

13. Wagner, S. et al. Bacterial type III secretion systems: a complex device for the delivery of bacterial effector proteins into eukaryotic host cells. FEMS Microbiol. Lett. 365, fny201 (2018).

14. Hu, B. et al. Visualization of the type III secretion sorting platform of Shigella flexneri. Proc. Natl Acad. Sci. USA 112, 1047-1052 (2015).

15. Hu, B., Lara-Tejero, M., Kong, Q., Galán, J. E. \& Liu, J. In situ molecular architecture of the Salmonella type III secretion machine. Cell 168, 1065-1074. e10 (2017).

16. Jackson, M. W. \& Plano, G. V. Interactions between type III secretion apparatus components from Yersinia pestis detected using the yeast twohybrid system. FEMS Microbiol. Lett. 186, 85-90 (2000).

17. Diepold, A. et al. Deciphering the assembly of the Yersinia type III secretion injectisome. EMBO J. 29, 1928-1940 (2010).

18. Diepold, A. et al. A dynamic and adaptive network of cytosolic interactions governs protein export by the T3SS injectisome. Nat. Commun. 8, 15940 (2017).

19. Lara-Tejero, M., Kato, J., Wagner, S., Liu, X. \& Galán, J. E. A sorting platform determines the order of protein secretion in bacterial type III Systems. Science 331, 1188-1191 (2011).

20. Nans, A., Kudryashev, M., Saibil, H. R. \& Hayward, R. D. Structure of a bacterial type III secretion system in contact with a host membrane in situ. Nat. Commun. 6, 10114 (2015).

21. Makino, F. et al. The architecture of the cytoplasmic region of type III secretion systems. Sci. Rep. 6, 33341 (2016)

22. Tachiyama, S. et al. The cytoplasmic domain of MxiG interacts with MxiK and directs assembly of the sorting platform in the Shigella type III secretion system. J. Biol. Chem. https://doi.org/10.1074/jbc.RA119.009125 (2019).

23. Muthuramalingam, M. et al. The structures of SctK and SctD from Pseudomonas aeruginosa reveal the interface of the type III secretion system basal body and sorting platform. J. Mol. Biol. https://doi.org/10.1016/j. jmb.2020.10.027 (2020).

24. Diepold, A., Kudryashev, M., Delalez, N. J., Berry, R. M. \& Armitage, J. P. Composition, formation, and regulation of the cytosolic C-ring, a dynamic component of the type III secretion injectisome. PLOS Biol. 13, e1002039 (2015).

25. Bernal, I. et al. Molecular organization of soluble type III secretion system sorting platform complexes. J. Mol. Biol. 431, 3787-3803 (2019).

26. Rocha, J. M. et al. Single-molecule tracking in live Yersinia enterocolitica reveals distinct cytosolic complexes of injectisome subunits. Integr. Biol. 10, 502-515 (2018).

27. Mikula, K. M., Kolodziejczyk, R. \& Goldman, A. Yersinia infection toolscharacterization of structure and function of adhesins. Front. Cell. Infect. Microbiol. 2, 169 (2013). 
28. Pepe, J. C., Wachtel, M. R., Wagar, E. \& Miller, V. L. Pathogenesis of defined invasion mutants of Yersinia enterocolitica in a BALB/c mouse model of infection. Infect. Immun. 63, 4837-4848 (1995).

29. Pepe, J. C. \& Miller, V. L. Yersinia enterocolitica invasin: A primary role in the initiation of infection. Proc. Natl Acad. Sci. USA 90, 6473-6477 (1993).

30. Uliczka, F. et al. Unique cell adhesion and invasion properties of Yersinia enterocolitica O:3, the most frequent cause of human yersiniosis. PLoS Pathog. 7, e1002117 (2011)

31. Leo, J. C., Oberhettinger, P., Schütz, M. \& Linke, D. The inverse autotransporter family: intimin, invasin and related proteins. Int. J. Med. Microbiol. 305, 276-282 (2015).

32. Han, Y. W. \& Miller, V. L. Reevaluation of the virulence phenotype of the inv yada double mutants of Yersinia pseudotuberculosis. Infect. Immun. 65, 327-330 (1997).

33. Meuskens, I., Saragliadis, A., Leo, J. C. C., Linke, D. \& Type, V. Secretion systems: an overview of passenger domain functions. Front. Microbiol. 10, 1-19 (2019).

34. Mühlenkamp, M., Oberhettinger, P., Leo, J. C. C., Linke, D. \& Schütz, M. S. S. Yersinia adhesin A (YadA) - Beauty \& beast. Int. J. Med. Microbiol. 305, 252-258 (2015).

35. Mota, L. J., Journet, L., Sorg, I., Agrain, C. \& Cornelis, G. R. Bacterial injectisomes: needle length does matter. Science 307, 2005 (2005).

36. Tertti, R., Skurnik, M., Vartio, T. \& Kuusela, P. Adhesion protein YadA of Yersinia species mediates binding of bacteria to fibronectin. Infect. Immun. 60 , 3021-3024 (1992).

37. Cornelis, G. R. The type III secretion injectisome. Nat. Rev. Microbiol. 4, 811-825 (2006).

38. Clerc, P., Baudry, B. \& Sansonetti, P. J. Plasmid-mediated contact haemolytic activity in Shigella species: correlation with penetration into HeLa cells. Ann. Inst. Pasteur Microbiol. 137A, 267-278 (1986).

39. Håkansson, S. et al. The YopB protein of Yersinia pseudotuberculosis is essential for the translocation of Yop effector proteins across the target cell plasma membrane and displays a contact-dependent membrane disrupting activity. EMBO J. 15, 5812-5823 (1996).

40. Armentrout, E. I. \& Rietsch, A. The type III secretion translocation pore senses host cell contact. PLOS Pathog. 12, e1005530 (2016).

41. Nauth, T. et al. Visualization of translocons in Yersinia type III protein secretion machines during host cell infection. PLOS Pathog. 14, e1007527 (2018).

42. Bohn, E., Sonnabend, M., Klein, K. \& Autenrieth, I. B. Bacterial adhesion and host cell factors leading to effector protein injection by type III secretion system. Int. J. Med. Microbiol. 309, 344-350 (2019).

43. Evans, D. F. et al. Measurement of gastrointestinal $\mathrm{pH}$ profiles in normal ambulant human subjects. Gut 29, 1035-1041 (1988).

44. McClements, D. J. \& Li, Y. Review of in vitro digestion models for rapid screening of emulsion-based systems. Food Funct. 1, 32 (2010).

45. Keller, B. et al. Yersinia enterocolitica exploits different pathways to accomplish adhesion and toxin injection into host cells. Cell. Microbiol. 17, 1179-1204 (2015).

46. Milne-Davies, B. et al. Life after secretion-Yersinia enterocolitica rapidly toggles effector secretion and can resume cell division in response to changing external conditions. Front. Microbiol. 10, 2128 (2019).

47. Patterson, G. H., Knobel, S. M., Sharif, W. D. \& Kain, S. R. \& Piston, D. W. Use of the green fluorescent protein and its mutants in quantitative fluorescence microscopy. Biophys. J. 73, 2782-2790 (1997).

48. Doherty, G. P., Bailey, K. \& Lewis, P. J. Stage-specific fluorescence intensity of GFP and mCherry during sporulation in Bacillus Subtilis. BMC Res. Notes 3, 303 (2010)

49. Grimm, J. B., Brown, T. A., English, B. P., Lionnet, T. \& Lavis, L. D. Synthesis of Janelia Fluor HaloTag and SNAP-tag ligands and their use in cellular imaging experiments. Methods Mol. Biol. 1663, 179-188 (2017).

50. Miesenböck, G., De Angelis, D. A. \& Rothman, J. E. Visualizing secretion and synaptic transmission with $\mathrm{pH}$-sensitive green fluorescent proteins. Nature 394, 192-195 (1998).

51. Morimoto, Y. V., Kojima, S., Namba, K. \& Minamino, T. M153r mutation in a ph-sensitive green fluorescent protein stabilizes its fusion proteins. PLOS ONE 6, e19598 (2011)

52. Hong, J. S., Hunt, A. G., Masters, P. S. \& Lieberman, M. A. Requirements of acetyl phosphate for the binding protein-dependent transport systems in Escherichia coli. Proc. Natl Acad. Sci. USA 76, 1213-1217 (1979).

53. Dechant, R. et al. Cytosolic $\mathrm{pH}$ is a second messenger for glucose and regulates the PKA pathway through V-ATPase. EMBO J. 29, 2515-2526 (2010).

54. Petrovska, I. et al. Filament formation by metabolic enzymes is a specific adaptation to an advanced state of cellular starvation. Elife 3, e02409 (2014).

55. Ross, J. \& Plano, G. V. A C-terminal region of Yersinia pestis YscD binds the outer membrane secretin YscC. J. Bacteriol. 193, 2276-2289 (2011).
56. Fukuoka, H., Sowa, Y., Kojima, S., Ishijima, A. \& Homma, M. Visualization of functional rotor proteins of the bacterial flagellar motor in the cell membrane. J. Mol. Biol. 367, 692-701 (2007).

57. Wieser, S. \& Schütz, G. J. Tracking single molecules in the live cell plasma membrane-Do's and Don't's. Methods 46, 131-140 (2008).

58. Diepold, A., Wiesand, U. \& Cornelis, G. R. The assembly of the export apparatus (YscR,S,T,U,V) of the Yersinia type III secretion apparatus occurs independently of other structural components and involves the formation of an YscV oligomer. Mol. Microbiol. 82, 502-514 (2011).

59. Abby, S. S. \& Rocha, E. P. C. The non-flagellar type III secretion system evolved from the bacterial flagellum and diversified into host-cell adapted systems. PLoS Genet. 8, e1002983 (2012).

60. Burgess, J. L., Case, H. B., Burgess, R. A. \& Dickenson, N. E. Dominant negative effects by inactive Spa47 mutants inhibit T3SS function and Shigella virulence. PLoS ONE 15, e0228227 (2020).

61. Young, G. M., Amid, D. \& Miller, V. L. A bifunctional urease enhances survival of pathogenic Yersinia enterocolitica and Morganella morganii at low pH. J. Bacteriol. 178, 6487-6495 (1996).

62. $\mathrm{Hu}, \mathrm{Y}$. et al. OmpR positively regulates urease expression to enhance acid survival of Yersinia pseudotuberculosis. Microbiology 155, 2522-2531 (2009).

63. Heroven, A. K. \& Dersch, P. Coregulation of host-adapted metabolism and virulence by pathogenic yersiniae. Front. Cell. Infect. Microbiol. 4, 146 (2014).

64. Chen, S., Thompson, K. M. \& Francis, M. S. Environmental regulation of Yersinia pathophysiology. Front. Cell. Infect. Microbiol. 6, 25 (2016).

65. Stingl, K. \& De Reuse, H. Staying alive overdosed: how does Helicobacter pylori control urease activity. Int. J. Med. Microbiol. 295, 307-315 (2005).

66. Slonczewski, J. L., Rosen, B. P., Alger, J. R. \& Macnab, R. M. pH homeostasis in Escherichia coli: measurement by $31 \mathrm{P}$ nuclear magnetic resonance of methylphosphonate and phosphate. Proc. Natl Acad. Sci. USA 78, 6271-6275 (1981).

67. Krulwich, T. A., Sachs, G. \& Padan, E. Molecular aspects of bacterial pH sensing and homeostasis. Nat. Rev. Microbiol. 9, 330-343 (2011).

68. Diepold, A. \& Wagner, S. Assembly of the bacterial type III secretion machinery. FEMS Microbiol. Rev. 38, 802-822 (2014).

69. Haneburger, I., Eichinger, A., Skerra, A. \& Jung, K. New insights into the signaling mechanism of the $\mathrm{pH}$-responsive, membrane-integrated transcriptional activator CadC of Escherichia coli. J. Biol. Chem. 286, 10681-10689 (2011)

70. Dawson, J. E. et al. Elucidation of a pH-folding switch in the Pseudomonas syringae effector protein AvrPto. Proc. Natl Acad. Sci. USA 106, 8543-8548 (2009).

71. Helenius, A., Kartenbeck, J., Simons, K. \& Fries, E. On the entry of semliki forest virus into BHK-21 cells. J. Cell Biol. 84, 404-420 (1980).

72. Mauracher, C. A., Gillam, S., Shukin, R. \& Tingle, A. J. pH-dependent solubility shift of rubella virus capsid protein. Virology 181, 773-777 (1991).

73. Taylor, D. J., Krishna, N. K., Canady, M. A., Schneemann, A. \& Johnson, J. E Large-scale, $\mathrm{pH}$-dependent, quaternary structure changes in an RNA virus capsid are reversible in the absence of subunit autoproteolysis. J. Virol. 76, 9972-9980 (2002)

74. Leake, M. C. et al. Stoichiometry and turnover in single, functioning membrane protein complexes. Nature 443, 355-358 (2006).

75. Lenn, T., Leake, M. C. \& Mullineaux, C. W. Clustering and dynamics of cytochrome bd-I complexes in the Escherichia coli plasma membrane in vivo. Mol. Microbiol. 70, 1397-1407 (2008).

76. Kumar, M., Mommer, M. S. \& Sourjik, V. Mobility of cytoplasmic, membrane, and DNA-binding proteins in Escherichia coli. Biophys. J. 98, 552-559 (2010).

77. Mika, J. T., Schavemaker, P. E., Krasnikov, V. \& Poolman, B. Impact of osmotic stress on protein diffusion in Lactococcus lactis. Mol. Microbiol. 94, 857-870 (2014).

78. Kimbrough, T. G. \& Miller, S. I. Contribution of Salmonella typhimurium type III secretion components to needle complex formation. Proc. Natl Acad. Sci. USA 97, 11008-11013 (2000).

79. Spreter, T. et al. A conserved structural motif mediates formation of the periplasmic rings in the type III secretion system. Nat. Struct. Mol. Biol. 16, 468-476 (2009).

80. Tusk, S. E., Delalez, N. J. \& Berry, R. M. Subunit exchange in protein complexes. J. Mol. Biol. https://doi.org/10.1016/j.jmb.2018.06.039 (2018).

81. Mueller, S. H., Spenkelink, L. M. \& van Oijen, A. M. When proteins play tag: the dynamic nature of the replisome. Biophys. Rev. 11, 641-651 (2019).

82. Kusmierek, M. et al. A bacterial secreted translocator hijacks riboregulators to control type III secretion in response to host cell contact. PLOS Pathog. 15, e1007813 (2019).

83. Koziolek, $\mathrm{M}$. et al. Investigation of $\mathrm{pH}$ and temperature profiles in the GI tract of fasted human subjects using the Intellicap ${ }^{\circledR}$ system. J. Pharm. Sci. 104, 2855-2863 (2015).

84. Pepe, J. C., Badger, J. L. \& Miller, V. L. Growth phase and low pH affect the thermal regulation of the Yersinia enterocolitica inv gene. Mol. Microbiol. 11 123-135 (1994). 
85. Cornelis, G. R. Yersinia type III secretion: Send in the effectors. J. Cell Biol. 158, 401-408 (2002).

86. Rappl, C., Deiwick, J. \& Hensel, M. Acidic pH is required for the functional assembly of the type III secretion system encoded by Salmonella pathogenicity island 2. FEMS Microbiol. Lett. 226, 363-372 (2003).

87. Yu, X.-J., McGourty, K., Liu, M., Unsworth, K. E. \& Holden, D. W. pH sensing by intracellular Salmonella induces effector translocation. Science $\mathbf{3 2 8}$ 1040-1043 (2010).

88. Yu, X.-J., Grabe, G. J., Liu, M., Mota, L. J. \& Holden, D. W. SsaV interacts with SsaL to control the translocon-to-effector switch in the Salmonella SPI-2 type three secretion system. MBio 9, e01149-18 (2018).

89. Sory, M.-P., Boland, A., Lambermont, I. \& Cornelis, G. R. Identification of the YopE and YopH domains required for secretion and internalization into the cytosol of macrophages, using the cyaA gene fusion approach. Proc. Natl Acad. Sci. USA 92, 11998-12002 (1995).

90. Kudryashev, M. et al. In situ structural analysis of the Yersinia enterocolitica injectisome. Elife 2, e00792 (2013).

91. Kaniga, K., Delor, I. \& Cornelis, G. R. A wide-host-range suicide vector for improving reverse genetics in Gram-negative bacteria: inactivation of the blaA gene of Yersinia enterocolitica. Gene 109, 137-141 (1991).

92. Thevenaz, P., Ruttimann, U. E. \& Unser, M. A pyramid approach to subpixel registration based on intensity. IEEE Trans. Image Process 7, 27-41 (1998).

93. Berg, H. C. \& Block, S. M. A miniature flow cell designed for rapid exchange of media under high-power microscope objectives. Microbiology 130, 2915-2920 (1984).

94. Hartmann, R. et al. Quantiative image analysis of microbial communitites with BiofilmQ. Nat. Microbiol. https://doi.org/10.1038/s41564-020-00817-4 (2020).

95. Nakamura, S. et al. Effect of intracellular ph on the torque?Speed relationship of bacterial proton-driven flagellar motor. J. Mol. Biol. 386, 332-338 (2009).

96. Edelstein, A., Amodaj, N., Hoover, K., Vale, R. \& Stuurman, N. Computer control of microscopes using $\mu$ Manager. Curr. Protoc. Mol. Biol. Chapter 14, Unit14.20 (2010).

97. Tokunaga, M., Imamoto, N. \& Sakata-Sogawa, K. Highly inclined thin illumination enables clear single-molecule imaging in cells. Nat. Methods 5, 159-161 (2008).

98. Wolter, S. et al. rapidSTORM: accurate, fast open-source software for localization microscopy. Nat. Methods 9, 1040-1041 (2012).

99. Schindelin, J. et al. Fiji: an open-source platform for biological-image analysis. Nat. Methods 9, 676-682 (2012).

100. Endesfelder, U., Malkusch, S., Fricke, F. \& Heilemann, M. A simple method to estimate the average localization precision of a single-molecule localization microscopy experiment. Histochem. Cell Biol. 141, 629-638 (2014).

101. Leo, J. C., Elovaara, H., Brodsky, B., Skurnik, M. \& Goldman, A. The Yersinia adhesin YadA binds to a collagenous triple-helical conformation but without sequence specificity. Protein Eng. Des. Sel. 21, 475-484 (2008).

102. Leo, J. C. et al. First analysis of a bacterial collagen-binding protein with collagen toolkits: promiscuous binding of YadA to collagens may explain how YadA interferes with host processes. Infect. Immun. 78, 3226-3236 (2010).

103. Saragliadis, A. \& Linke, D. Assay development for the discovery of smallmolecule inhibitors of YadA adhesion to collagen. Cell Surf. 5, 100025 (2019).

104. Iriarte, M. \& Cornelis, G. R. YopT, a new Yersinia Yop effector protein, affects the cytoskeleton of host cells. Mol. Microbiol. 29, 915-929 (1998).

105. Diepold, A., Wiesand, U., Amstutz, M. \& Cornelis, G. R. Assembly of the Yersinia injectisome: the missing pieces. Mol. Microbiol. 85, 878-892 (2012).

\section{Acknowledgements}

We thank Nicholas Dickenson (Utah State University, Logan, USA) for the kind sharing of Shigella flexneri GFP-Spa47, Sophie Bleves (Aix-Marseille University, FR) for the
Pseudomonas aeruginosa PAO1 strain, Marc Erhardt (Humboldt University Berlin, Germany), Tohru Minamino (Osaka University, Japan), and Gero Miesenböck (University of Oxford, UK) for the pHluorin ${ }_{\text {M153R }}$ DNA, Luke Lavis (Janelia Research Campus, USA) for the kind donation of Janelia Fluor dyes, and Malte Buchholz (University of Marburg, Germany) for helpful discussions about gastrointestinal infection pathways. We are also grateful to Carlos Helbig and Bartosz Turkowyd (Max Planck Institute Marburg, Germany and Carnegie Mellon University, USA) for analysis scripts This work was supported by the Max Planck Society. It was also funded by the Horizon 2020 Innovative Training Network "ViBrANT" (to D. Linke)

\section{Author contributions}

S.W. performed the majority of the experiments and data analysis and participated in study design and writing the manuscript. A.B. performed and analyzed the sptPALM experiment with support from S.W. H.J. provided coding for the automated spot detection. L.S., D. Lampaki and E.E. assisted in experiments and strain generation. I.M performed the YadA binding experiments and participated in proofreading the manuscript. D. Linke, K.D., and U.E. provided supervision and participated in discussions and proofreading. A.D. conceived and designed the study, performed experiments and data analysis and wrote the manuscript.

\section{Funding}

Open Access funding enabled and organized by Projekt DEAL.

\section{Competing interests}

The authors declare no competing interests.

\section{Additional information}

Supplementary information The online version contains supplementary material available at https://doi.org/10.1038/s41467-021-21863-4.

Correspondence and requests for materials should be addressed to A.D.

Peer review information Nature Communications thanks Marcia Goldberg and the other, anonymous reviewers for their contribution to the peer review of this work. Peer review reports are available.

Reprints and permission information is available at http://www.nature.com/reprints

Publisher's note Springer Nature remains neutral with regard to jurisdictional claims in published maps and institutional affiliations.

Open Access This article is licensed under a Creative Commons Attribution 4.0 International License, which permits use, sharing, adaptation, distribution and reproduction in any medium or format, as long as you give appropriate credit to the original author(s) and the source, provide a link to the Creative Commons license, and indicate if changes were made. The images or other third party material in this article are included in the article's Creative Commons license, unless indicated otherwise in a credit line to the material. If material is not included in the article's Creative Commons license and your intended use is not permitted by statutory regulation or exceeds the permitted use, you will need to obtain permission directly from the copyright holder. To view a copy of this license, visit http://creativecommons.org/ licenses/by/4.0/.

(C) The Author(s) 2021 